\title{
SAN PEDRO DE ATACAMA Y LA CUESTIÓN TIWANAKU EN EL NORTE DE CHILE: IMPRESIONES A PARTIR DE UN CLÁSICO ESTUDIO CERÁMICO Y LA EVIDENCIA BIOARQUEOLÓGICA ACTUAL (400-1.000 D.C.)
}

\author{
SAN PEDRO DE ATACAMA AND THE TIWANAKU ISSUE \\ IN NORTHERN CHILE: VIEWS FROM A CLASSIC CERAMIC STUDY \\ AND NEW BIOARCHAEOLOGIAL DATA (AD 400-1,000) \\ Mauricio Uribe R. ${ }^{1}$, Francisca Santana-Sagredo ${ }^{2}$, Anahí Maturana F., \\ Sergio Flores $C .{ }^{1}$ y Carolina Agüero $P^{3}$
}

\begin{abstract}
En las últimas décadas los arqueólogos han tendido a examinar la problemática Tiwanaku fuera del núcleo altiplánico, principalmente en términos de acceso a recursos y/o complementariedad ecológica y religiosa, entre un centro y su periferia. Sin embargo, dominados por las ideas de Estados o imperios, estas reconstrucciones adolecen de reduccionismo económico e iconográfico, en perjuicio del entendimiento de los fenómenos políticos andinos. Dentro de esta problemática, retomamos la relación entre Tiwanaku y San Pedro de Atacama a partir de un nuevo estudio de la cerámica negra pulida de los cementerios de Solcor y Coyo, en razón del carácter fundacional que Le Paige y Tarragó le imprimieron a esta alfarería para abordar el impacto altiplánico en la región. Este análisis, en conjunto con la reciente evidencia bioarqueológica obtenida por este equipo y otros, nos permiten repensar este vínculo y avanzar hacia la compresión de una realidad social mucho más dinámica, heterogénea y desigual.
\end{abstract}

Palabras claves: San Pedro de Atacama, Período Medio, cerámica negra pulida, bioarqueología.

For many years, archaeologists have examined the Tiwanaku phenomenon outside the Titicaca basin. The research has been mainly focused on economical systems, and religious and ecological complementarity between centers and their periphery in the Andes. However, dominated by our conceptions of state and empire, those reconstructions are biased by an economic and iconographic deterministic point of view, in detriment of understanding the diversity of the Andean political phenomena. Here, we reconsider the relationship between Tiwanaku and San Pedro de Atacama through a new study of the classic black-polished pottery from the cemeteries of Solcor and Coyo, taking into account the foundational role assigned to this pottery type by different archaeologist to understand the influence of the Altiplano in the Atacama region. The results of this pottery analysis and our bioarchaeology data suggest a more heterogeneous and unequal social reality for San Pedro de Atacama as a consequence of their own local dynamics.

Key words: San Pedro de Atacama, Middle Horizon, polished black pottery, bioarchaeology.

Por medio de este estudio retomamos la problemática Tiwanaku en San Pedro de Atacama (Figura 1), puesto que las interpretaciones realizadas sobre el periodo Medio todavía son insuficientes y porque, según veremos, nuevas evidencias bioarqueológicas aportan con nuevos datos y conclusiones que obligan a repensar el periodo Medio en los oasis atacameños. El estado actual de la investigación mantiene una concepción jerárquica y conservadora de la relación entre ambas entidades (San Pedro y Tiwanaku), lo que ha redundado en explicaciones todavía simples de la complejidad social de la época. Según estas concepciones, la historia de San Pedro por una u otra razón depende de la existencia de Tiwanaku y, bajo un claro sesgo occidental, su desarrollo comunitario se encuentra subordinado al proyecto del Estado (Berenguer y Dauelsberg 1989; Stanish 2002). No obstante existen enfoques alternativos al respecto (Niemeyer et al. 2015; Torres-Rouff y Hubbe 2013), estos tampoco han podido superar el paradigma, probablemente porque la misma cultura material estudiada tiene

1 Departamento de Antropología, Facultad de Ciencias Sociales, Universidad de Chile, Santiago, Chile. mur@uchile.cl; anahi.mtfez@gmail.com; sfloresc@uchile.cl

2 Research Laboratory for Archaeology and the History of Art, University of Oxford, Oxford, UK. francisca.santanasagredo@rlaha.ox.ac.uk

3 Instituto de Investigaciones Arqueológicas y Museo R.P. Gustavo Le Paige S.J. (IIAM), Universidad Católica del Norte, San Pedro de Atacama, Chile.maguero@ucn.cl 
una carga simbólica e ideológica que conduce la mirada hacia esas concepciones de mundo. Por lo mismo, la identidad y la diversidad no se valoran adecuadamente en términos del significado social para comprender que, como en cualquier hecho histórico, la complejidad del período se gestó a partir de la microfísica y peculiares dinámicas del poder (Foucault 1992; Zizek 2003).

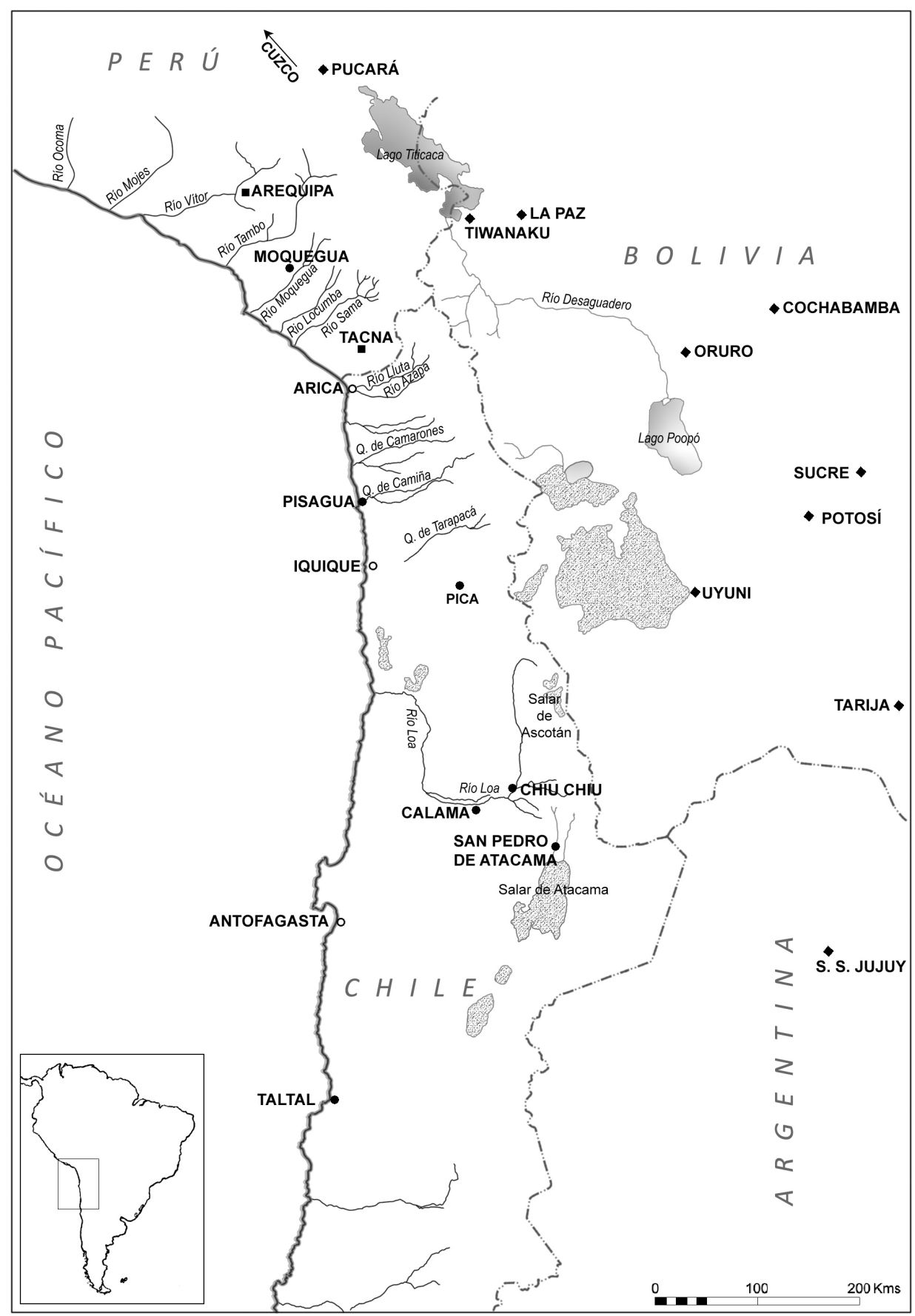

Figura 1. Mapa de los Andes Centro Sur y principales localidades del período Medio mencionadas en el texto (Fuente: Uribe y Agüero 2001).

Map of the South Central Andes and principal localities of the Middle Period mentioned in the text (From: Uribe y Agüero 2001). 
Dentro de esta problemática general y manteniendo una posición crítica respecto de la misma (Uribe 2004; Uribe y Agüero 2001, 2004), nos propusimos retomar la relación entre Tiwanaku y San Pedro de Atacama, en tanto el punto más lejano al sur de los Andes donde se concentra evidencia de esta cultura y época. Para ello nos centramos en los estudios arqueológicos y bioantropológicos de los cementerios de Solcor y Coyo, correspondientes a dos puntos claves para evaluar el impacto Tiwanaku y las dinámicas locales (Berenguer y Dauelsberg 1989; Costa y Llagostera 1994; Llagostera et al. 1988; Tarragó1989).

Sin desconocer lo anterior, nos parece posible develar una realidad distinta. En efecto, gracias a la cerámica y al apoyo de la biarqueología hoy se puede visualizar una sociedad sanpedrina en constante tensión y con importantes signos de conflicto interno, los que se desenvolvían en un juego que enfrentaba al colectivo y al individuo; a la tradición representada por el chamanismo y los sujetos emergentes ejemplificados por aquellos que mantenían contactos a larga distancia y accedían a recursos foráneos por intercambio. A modo de hipótesis, consideramos que el normado y emblemático estilo de la alfarería negra pulida de San Pedro, en conjunto con otros datos, permiten ahondar en estas dinámicas (Gosselein 1998, 2008). A nuestro juicio, su clara identidad y aparente homogeneidad, a nivel de objeto y de contexto, darían cuenta de una imagen equívoca de la sociedad, invisibilizando las contradicciones internas que se experimentaron en aquella época y favoreciendo, hasta la actualidad, ideas de unidad étnica, armonía social, enriquecimiento económico, liderazgo regional, entre otros (Llagostera 1996; Núñez 1992).

\section{La Arqueología del Período Medio y San Pedro de Atacama}

$\mathrm{Al}$ igual que en el resto de los Andes Centro Sur, la problemática Tiwanaku es sumamente conocida en la prehistoria del Norte de Chile (Berenguer et al. 1980; Berenguer y Dauelsberg 1989). Es claro que la distribución de la iconografía de Tiwanaku, al menos desde el 500 d.C., abarcó una vasta área (extremo sur del Perú, oeste de Bolivia, norte de Chile y Noroeste Argentino), configurando la órbita cultural de lo que se entiende como el primer Estado altiplánico prehispánico (Stanish 2002).
Por lo tanto, existe consenso en que Tiwanaku fue protagonista del desarrollo de la complejidad andina; no obstante, todavía no hay acuerdo en cuanto a la naturaleza de su dispersión, supremacía política $\mathrm{y}$, en consecuencia, de una supuesta expansión territorial. Por lo mismo, esta situación ha sido interpretada de diferentes maneras, ya sea como resultado de un Estado expansivo o imperio, un centro económico, un movimiento religioso, un lugar simbólico e identitario, una confederación multiétnica, etc. (Albarracín-Jordán 1996; Bennett 1956 [1934]; Berenguer 1998; Browman 1984; Conklin 1991; Cook 1994; Goldstein 1995-96; Isbell 1983; Isbell y Cook 1987; Janusek 2004, 2008; Kolata 1993; Korpisaari 2006; Menzel 1964; Mujica 1985; Núñez y Dillehay 1995; Ponce 1972; Stanish 2002; Wallace 1980).

En las últimas décadas los arqueólogos han tendido a examinar la problemática Tiwanaku fuera del núcleo altiplánico, principalmente en términos de estrategias de acceso a recursos y complementariedad económica, o bien de un sistema religioso compartido, en consonancia con el modelo de control vertical de Murra (1972; Masuda et al. 1985; Niemeyer et al. 2015). En la cuenca del Titicaca se ha avanzado notablemente en términos de la comprensión sociopolítica de la génesis y del fenómeno Tiwanaku, apelando desde la economía política o la teoría de la práctica a las dinámicas del liderazgo, la competencia, la identidad y la etnicidad (Janusek 2004, 2008; Stanish 2002); sin embargo, no ha ocurrido lo mismo con la periferia y menos aún con los espacios más lejanos donde ha sido notada su influencia.

Salvo pocas excepciones (Owen 2005), estas reconstrucciones adolecen de un reduccionismo formal en perjuicio del entendimiento y subordinación de las prácticas políticas e ideológicas que implicaron fenómenos de esta clase, de antemano concebidos como Estados expansivos o imperiales. De este modo, se mantiene la idea generalizada de que Tiwanaku y su esfera de influencia formaron un megasistema con relaciones centro-periferia desde una perspectiva ecológica y políticamente centralizada (Kolata 1993). Las investigaciones, especialmente norteamericanas y ciertas miradas nacionales andinas, insisten que a lo largo de ese primer milenio en la cuenca del lago Titicaca existió una sociedad agroganadera, técnicamente avanzada, socialmente estratificada y cuyo principal centro (urbano y religioso) fue la capital de una de las entidades expansivas más 
grandes de la civilización andina (Berenguer 2000; Ponce 1972; Posnansky 1957; Stanish 2002). Sin embargo, estas interpretaciones y los énfasis de cada una de ellas fallan porque la supuesta expansión es explicada de manera unilateral, exclusivamente solo del núcleo o desde la periferia.

\section{Una mirada arqueológica convencional}

Para el caso de San Pedro de Atacama (Figura 2), las evidencias arqueológicas sugieren contactos con el altiplano desde mediados del período Formativo (fases Toconao y Sequitor), ocurriendo el momento de mayor interacción entre los años 400 y 1.000 d.C., correspondientes a las fases Quitor y Coyo del Período Medio (Berenguer et al. 1986; Tarragó 1989; Torres-Rouff y Hubbe 2013). Los contextos funerarios ubicados entre las fases Toconao y Sequitor, alrededor de los años 350 a.C. y 400 d.C., presentan las primeras tabletas para el consumo de alucinógenos con iconografía altiplánica de personajes de perfil contorsionados con nariz prominente y elementos de sacrificio en las manos como hachas y cabezas humanas, asociadas a alfarería local roja y negra pulida (Le Paige 1965; Llagostera 2015; Orellana 1984, 1985). Tales evidencias han sugerido una participación creciente de San Pedro en una amplia red de tráfico que se relacionaría con un aumento de la ocupación e intensificación agrícola entre los ríos San Pedro y Vilama (Llagostera 1996; Núñez 1992); en paralelo al crecimiento de cementerios en cada oasis, la popularización de la cerámica negra pulida y el auge de la industria en madera (p.ej., parafernalia alucinógena, cucharas y otros objetos).

Se asumió, entonces, que en San Pedro se produjo un comportamiento homogéneo y generalizado, lo que se tradujo básicamente en dos modelos para explicar el origen de objetos de estilo Tiwanaku. El primero de ellos está marcadamente influenciado por el modelo de Murra (Mujica 1985), aduciendo un contacto directo entre la población atacameña y la altiplánica a través de la instalación de colonias foráneas en los oasis y el establecimiento de un fuerte dominio religioso (Benavente et al. 1986; Thomas et al. 1984, 1985; Torres y Conklin 1995). El segundo refiere a la existencia de contactos indirectos entre los oasis atacameños y las poblaciones del altiplano, pero intermediados por grupos meridionales mediante alianzas o confederaciones envueltas en redes de tráfico y caravanas con fines económicos como religiosos
(Berenguer 2000; Browman 1984; Llagostera 1996; Núñez 1984, 1992; Núñez y Dillehay 1995). Tales contactos implicarían una negociación manejada por las cabezas o principales de cada grupo, en términos de relaciones de "clientelaje" entre élites, configurando una amplia esfera de intercambio a base de caravanas de llamas dentro de lo que se ha denominado la ultra-periferia Tiwanaku (Berenguer 2000; Berenguer y Dauelsberg 1989; Kolata 1993; Stanish 2002).

Durante esos momentos, San Pedro ingresaría a circuitos de interacción e intercambio con el altiplano del Titicaca, pero sobre todo integraría parte de una red mayor con el Altiplano Meridional y el Noroeste Argentino (Llagostera 1995). Todo lo cual adquiriría plena definición entre los años 400 y 500 d.C. cuando se dio paso a la fase Quitor asociada a la alfarería negra pulida clásica, el florecimiento del trabajo en madera con iconografía propia y el claro ingreso de materiales Tiwanaku a los oasis, los que pronto traspasarían su imaginería al complejo alucinógeno local (Horta 2014; Le Paige 1964; Llagostera 2006; Tarragó 1989; Thomas et al. 1984; Torres y Conklin 1995). Tal situación ha llevado a afirmar la ampliación del intercambio, cuyo control comenzó a centralizarse en los oasis, desenvolviéndose una gran complejidad sociopolítica (Núñez 1992; Llagostera 1996). Lo anterior sería elocuente en los objetos de oro junto a cerámica negra pulida en las tumbas de Larache o Casa Parroquial y otros artefactos de metal en los cementerios de Quitor y Solor que demostrarían la existencia de jerarquías locales capaces de mantener relaciones foráneas de alto nivel (Lechtman y Macfarlane 2005; Le Paige 1961; Salazar et al. 2011; Stovel 2001).

Sin embargo, sería en la fase Coyo, entre los años 750 y 1.000 d.C., cuando en San Pedro se concentran las evidencias Tiwanaku. Paralelo a esto se habrían sucedido ciertos cambios en la producción alfarera local como un posible desplazamiento de la fina cerámica negra pulida por otra de color gris, más gruesa y "casi" pulida, junto con la aparición de otros tipos locales (p.ej., mitad negros-mitad rojos, incisos y/o grabados) y algunos ejemplares Tiwanaku (Munizaga 1963; Tarragó 1989). Muchas de estas manifestaciones se concentrarían en el cementerio Coyo Oriente, dando nombre a la fase respectiva y mostrando, especialmente por medio del complejo alucinógeno, una marcada influencia altiplánica o "tiwanakización" de la localidad (Llagostera 2006). Esta intensificación de vínculos foráneos 


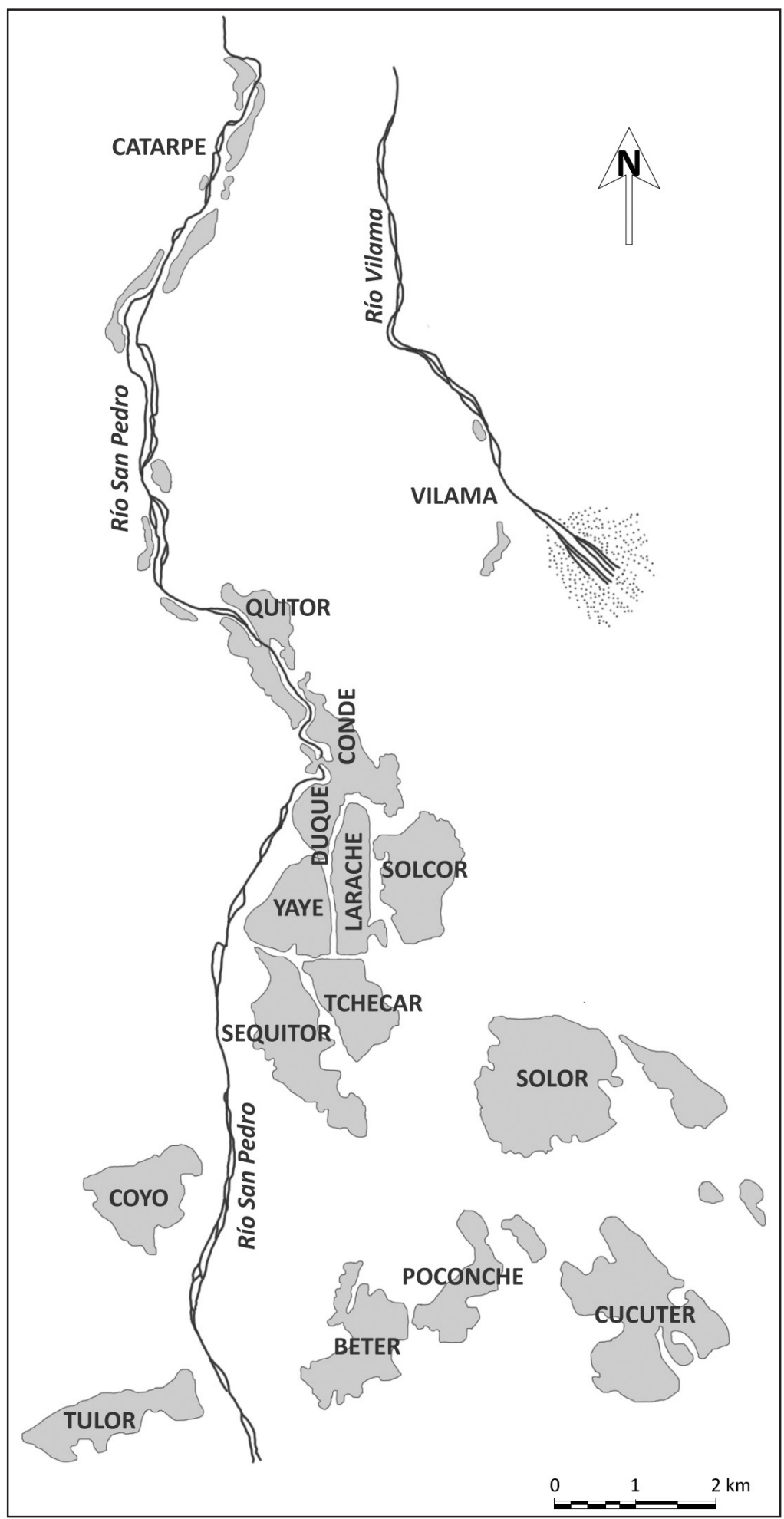

Figura 2. Mapa de la localidad de San Pedro de Atacama y principales sitios del período Medio mencionados en el texto (Fuente: Costa y Llagostera 2014).

Map of San Pedro de Atacama and the principal sites of the Middle Period mentioned in the text (From: Costa y Llagostera 2014). 
se asociaría con un desplazamiento de la población local hacia sectores no ocupados durante el momento anterior; lo que al parecer se habría relacionado con intereses más específicos como la minería, según lo sugiere una importante presencia de martillos líticos y procesamiento de cobre en otros sectores de Coyo (Costa y Llagostera 1994). Un panorama tan sofisticado como este ha sido sugerente de un sistema sociopolítico encabezado por líderes o linajes con poder de acumulación, representantes de los grupos locales o de condición extranjera que eran los responsables de establecer alianzas. Estos últimos, muy probablemente, lo harían a través de estrategias de parentesco, intercambio y chamanismo debido a la vinculación de objetos exóticos y/o foráneos con determinados tipos de deformación craneana y elaborados ejemplares del complejo alucinógeno asociados a determinados individuos, especialmente masculinos (Berenguer et al. 1980; Horta 2014; Llagostera 1996).

Desde la perspectiva de Llagostera (2015), San Pedro desarrolló un patrón político, social y cultural propio que habría integrado la realidad circumpuneña desde el Formativo hasta consolidarse en el período Medio, donde Tiwanaku ayudó a reforzar esta estructura. En efecto, sin la necesidad de establecer colonias como en otras partes de los Andes, la entidad altiplánica habría impulsado cambios al interior de la sociedad local, dando mayor prestigio a ciertos grupos e introduciendo una nueva ideología que reforzaba el régimen de jefaturas. Por consiguiente, la alta eficiencia del sistema implementado habría permitido que los oasis atacameños alcanzaran niveles de desarrollo más complejos y mejores condiciones de vida que los imaginables en un territorio tan desértico y marginal (Berenguer 2000; Berenguer y Dauelsberg 1989). Sin embargo, todavía resulta escaso e insuficiente el conocimiento de la estructura y funcionamiento de esta sociedad para permitirnos una real comprensión de las conexiones a tan larga distancia entre las entidades del Titicaca y el territorio circumpuneño. En particular, porque se mantiene la idea de una población subordinada y dependiente de los intereses externos, lo que no permite percibir la capacidad de agencia de la sociedad local ni sus formas de participación y contribución a la formación de un orden político superior. De este modo, con mayor o menor énfasis, el esquema anterior ha sido objeto de crítica por parte de la arqueología debido a que promueve una idea homogénea y la simplificación del fenómeno andino (Albarracín-Jordán 1996; Uribe y Agüero 2001).

\section{La mirada bioarqueológica renovadora}

No obstante aquello, algunos estudios bioarqueológicos como los realizados para los conocidos cementerios de Solcor han postulado la existencia de una mayor variabilidad al interior de la población local, al menos a nivel funerario (Bravo y Llagostera 1986; Knudson 2007; Nado et al. 2012). En la actualidad, esto ha permitido fortalecer la idea que los grupos autóctonos de San Pedro de Atacama manejaron los vínculos con Tiwanaku de diversas formas durante el período Medio. Estos estudios han distinguido grupos que exhiben cierta riqueza de ofrendas e incorporan de manera diferencial objetos de estilo Tiwanaku (Nado et al. 2012). Por ejemplo, los individuos enterrados en Solcor 3 , a diferencia de aquellos de Solcor Plaza, muestran tumbas mucho más ricas respecto del total de piezas presentes (p.ej., artefactos de metal y tabletas para alucinógenos). Solcor 3, además, expresa una gran apertura a los materiales Tiwanaku (p.ej., tejidos y tabletas). Sin embargo, la correlación entre tumbas con gran concentración de objetos y la presencia de bienes Tiwanaku es bastante débil; o sea, entierros ricos no contienen necesariamente piezas del estilo altiplánico. Por otra parte, la proporción de individuos enterrados con objetos foráneos no-Tiwanaku no muestran diferencias significativas entre uno y otro sector de Solcor.

Una situación análoga ocurriría con el cementerio de Larache, donde se han encontrado tumbas con ofrendas Tiwanaku, pero los individuos enterrados junto a ellas no presentan evidencias de ser foráneos ni del Titicaca. En tanto que los individuos no locales o foráneos de Larache no estarían asociados a piezas altiplánicas (Knudson y Torres-Rouff 2014). En general, por lo tanto, las tumbas con piezas Tiwanaku constituirían casos muy particulares y vinculados indistintamente a personas locales o no foráneas. De manera complementaria, los isótopos de estroncio han permitido determinar la presencia de cinco individuos con valores de ${ }^{87 / 86} \mathrm{Sr}$ que sugieren orígenes de al menos dos regiones distintas, unos del altiplano y otros foráneos a San Pedro y al altiplano mismo. En general, la variación del $\mathrm{Sr}$ sería considerable respecto de los valores locales, sugiriendo diversidad de poblaciones y un radio 
mayor del territorio manejado por las comunidades atacameñas durante el periodo Medio.

Los estudios relativos a deformación craneana, por su parte, señalan la popularidad de esta práctica y la existencia de múltiples estilos, destacando que las proporciones entre cráneos deformados y no deformados no difieren mucho entre cementerios (Costa et al. 1995). Pero también se advierten ciertas diferencias dentro de los ejemplares deformados (circulares y tabulares), a partir de lo cual se han propuesto orígenes locales y foráneos para los individuos que detentan una determinada deformación (Torres-Rouff 2002). Por ejemplo, en Solcor Plaza serían más comunes las formas circulares que se consideran características del altiplano; en tanto, las tabulares tendrían un largo desarrollo local, destacando en Solcor 3. Integrando las evidencias, Torres-Rouff (2002), como también Nado et al. (2012), han concluido que la presencia de objetos foráneos y la alta variedad de deformación estarían asociadas a individuos preferentemente locales, según su señal isotópica del Sr. No obstante, aunque dominante a nivel local, la deformación tabular también aparece entre sujetos foráneos, así como la deformación circular. De cualquier forma, casi ninguno de estos individuos foráneos fue enterrado con objetos Tiwanaku, al menos en Solcor (Llagostera et al. 1988).

Respecto de la dieta, los análisis de isótopos de carbono realizados en esmalte dental (Nado et al. 2012) son indicativos de que la población de San Pedro mantuvo una dieta relativamente rica en maíz $\left(\mathrm{C}_{4}\right)$ complementada con otras plantas cultivadas $\left(\mathrm{C}_{3}\right)$. Sin embargo, también se han detectado diferencias significativas en el consumo de maíz, ya que en Solcor Plaza se registra una ingesta mayor que en Solcor 3. A pesar de esta situación, los individuos foráneos de ambos cementerios (dos en Solcor 3 y tres en Solcor Plaza) no mostrarían mayor diferencia respecto de la dieta local. No obstante, evidencia como esta se usó para postular una dieta distinta a principios y fines del período, provocada por el contacto con Tiwanaku, lo cual se ha relacionado con un incremento del consumo de maíz y proteínas, como sugirieron Costa et al. (Cocilovo et al. 2014; Costa et al. 2004; Neves y Costa 1997).

De acuerdo con estos antecedentes, hoy las investigaciones proponen la existencia de una compleja negociación de la presencia foránea en San Pedro de Atacama (Nado et al. 2012), aunque manteniendo la visión de una potente influencia Tiwanaku en algunos oasis (Llagostera et al. 1988). Se presume que la mayoría de los individuos enterrados tienen una identidad atacameña o sanpedrina, reflejada en el tratamiento mortuorio y el estilo funerario. Incluso se plantea que esta identidad fue desarrollada a nivel de subgrupos; de tal modo que las distinciones específicas habrían sido resueltas a través del acceso y empleo de símbolos identitarios lejanos. Desde esta perspectiva, los personajes foráneos se habrían incorporado a la dinámica local, participando y desplegando elementos de identidad atacameña.

Bajo este supuesto, la concentración de deformación anular en Solcor Plaza es entendida como una señal corporal de expresar sus nexos con el Titicaca. Al contrario, la población de Solcor 3 habría hecho lo mismo pero mediante la adquisición de objetos Tiwanaku. Por lo tanto, se entiende que la falta de correlación entre la deformación anular y los bienes altiplánicos respondería a estrategias diferenciadas para establecer su identidad en relación con símbolos foráneos y poderosos. Igualmente, los alimentos como el maíz y la mayor provisión de proteínas obtenidas del ganado altiplánico pudieron actuar como símbolos para mostrar estas conexiones.

En este sentido, los resultados de los isótopos, y en particular los de $\mathrm{Sr}$, son considerados la expresión de una migración hacia San Pedro más compleja que la planteada hasta ahora, apoyando la hipótesis de una diáspora Tiwanaku por distintas zonas del sur de los Andes (Goldstein y Owen 2001; Owen 2005). Lo anterior sería coherente con otros análisis bioarqueológicos que han afirmado una mayor diversidad genética durante el mismo periodo (Varela y Cocilovo 2011). Por lo mismo, los contextos demostrarían cierta variabilidad en el comportamiento de los individuos foráneos, quienes asimilarían elementos de las tradiciones locales. Desde esta perspectiva, al menos en la muerte, estos no habrían sido tratados como extranjeros sino como parte de la comunidad sanpedrina. Habrían adquirido la cultura material local y con ello su identidad, en vez de mantener su carácter y el monopolio de los objetos relacionados con su lugar de origen (Nado et al. 2012). El uso de bienes Tiwanaku, entonces, no solo estaría ligado a la presencia de los inmigrantes del altiplano, sino a las dinámicas de la sociedad local y sus competencias internas, llevándolos finalmente a participar de la periferia altiplánica. Por lo tanto, más que obedecer a una 
condición impuesta hegemónicamente del centro a la periferia, los grupos de San Pedro habrían manejado la integración de agentes foráneos y manipulado los indicadores materiales de sus contactos en favor de su propia reproducción e identidad.

Finalmente, la variabilidad bioantropológica mencionada previamente ha sido correlacionada por Torres-Rouff y Hubbe (2013) con la ocupación de los diferentes cementerios por medio de una evaluación cronológica de los oasis o ayllus atacameños. A partir de 53 fechados de radiocarbono 14, realizados en muestras de individuos de los ayllus de San Pedro y Toconao, los autores han confirmado una ocupación continua de estos a través del tiempo. Se destacan los casos de los ayllus de Quitor y Solcor con fechas que abarcan desde el Formativo Tardío hasta el Intermedio Tardío, contradiciendo la clásica asociación entre fase cronológica y un ayllu en particular (Berenguer et al. 1986; Tarragó 1989), a partir de lo cual han propuesto que los cementerios fueron utilizados de manera contemporánea. Por lo tanto, se observa una variabilidad mucho mayor tanto a nivel intra como inter sitios en términos sincrónicos y diacrónicos, lo que ha tendido a quedar oculto por adscribir cada ayllu a una fase particular. En suma, Torres-Rouff y Hubbe (2013) argumentan que las ocupaciones dentro y entre oasis serían independientes en el contexto espacio-temporal, sin responder a un patrón único "atacameño" que tiende a homogeneizar los cementerios de San Pedro. Todos estos aspectos se suman y complementan con la alta diversidad observada en la evidencia bioantropológica asociada a diferencias de organización social y estatus, así como la relación o ausencia de ella con individuos foráneos, tanto provenientes de Tiwanaku como de otras regiones.

\section{Un Contrapunto Arqueológico}

Los avances desarrollados por la bioarqueología en esta problemática han sido sumamente atractivos, porque se entienden desde una antropología del cuerpo y del individuo (Agarwal 2012; Stone 2012), la que aún ha sido poco desarrollada por la disciplina en el norte de Chile. Ahora bien, el manejo del cuerpo por la sociedad y la cultura también denota una situación errática, puesto que muchas veces implica caracteres impuestos a temprana edad y difíciles de manipular por la voluntad individual, impidiendo visualizar otras dimensiones del fenómeno social. A diferencia de lo anterior, la cultura material permite realizar una lectura complementaria del hecho biológico y social, ya que corresponde a una creación individual dentro de ciertas pautas colectivas, cuyos productos se pueden repetir, usar y manipular según distintos intereses, contextos y momentos. Por lo mismo, la participación de objetos como la cerámica en las dinámicas humanas es muy significativa, ya que su presencia, consumo y descarte dependen esencialmente de motivaciones sociales (Gosselain 1998; Uribe 2011). Por tal razón, aunque es un elemento muy parcial de la realidad, nos parece apropiado el estudio de la cerámica ritual y funeraria de San Pedro de Atacama para actualizar la reflexión en torno a la sociedad del período Medio, comparando los datos cerámicos, ciertos indicadores bioarqueológicos y nuestras nociones de complejidad social (McGuire 1983; Uribe 2006). Esto último será entendido bajo un razonamiento que, desde la teoría social de la estructuración y la práctica (Bourdieu 1977; Giddens 1995), concibe los conceptos de colectivo e individuo así como complejidad y desigualdad, estrechamente imbricados:

La evolución, entonces, es la historia de la complejidad social que desde una perspectiva metodológica requiere establecer para su comprensión, entre otros aspectos, la interacción entre heterogeneidad y desigualdad, entendiendo que a mayor heterogeneidad la sociedad no necesariamente es más desigual, sino al revés y que en cualquier caso es más o menos compleja... por lo que la sociedad compleja se constituye por esa gran diversidad social y siempre es desigual (Uribe 2006:95).

\section{Algunas precisiones metodológicas}

Este acercamiento a la problemática se ha encauzado a través del examen de las colecciones y cerámica de los cementerios de Solcor 3 y Coyo Oriente, las cuales componen una muestra que suma más de 400 vasijas. La metodología comprendió el registro del material y su tipología, elaboración de bases de datos, selección de atributos o variables a estudiar por medio de estadística descriptiva como porcentajes o frecuencias que fueron vertidos en gráficos y tablas para proveer una clasificación final. En primer lugar, esta clasificación se basó 
en un reconocimiento visual macroscópico y bajo lupa de las piezas enteras o fragmentadas, realizando una descripción estandarizada de las pastas, los tratamientos de superficie, la morfología y decoración de las vasijas (Uribe 2004; Varela et al. 1993). Se puso énfasis a la observación equilibrada de los aspectos tanto tecnológicos como estéticos (p.ej., superficie y decoración), evitando las distorsiones que generalmente promueven los atributos estilísticos por sí solos. Para sistematizar estos registros, en una segunda etapa, se construyeron bases de datos donde se integró y ordenó cuantitativamente la información seleccionada, utilizando el número de piezas o fragmentos indicativos de vasijas completas, respectivamente. Además se realizaron apreciaciones acerca del modo cómo se habría depositado la alfarería, considerando la forma de las vasijas, la abundancia o escasez del material, su condición nueva o usada, su relación con otras piezas presentes en las tumbas y cronología, lo cual proporcionó información significativa acerca de las actividades y los contextos que se desarrollaron sincrónica o diacrónicamente en cada sitio. En definitiva, las pastas, tratamiento y acabado de las superficies de la cerámica en conjunto con sus características depositacionales constituyen los atributos relevantes que, vistos de manera simultánea, nos permiten definir la tradición alfarera negra pulida de San Pedro de Atacama.

En paralelo y con el fin de complementar nuestros planteamientos con una variable independiente, hemos realizado análisis de isótopos estables de carbono y nitrógeno para muestras de costillas y falanges de Solcor $3(n=30)$ y Coyo $3(n=22)$, cuyo tratamiento fue realizado en laboratorios de la Universidad de Cornell. La elección de las muestras se realizó bajo los siguientes criterios: (a) selección exclusiva de individuos adultos, para evitar problemas de interpretación isotópica en relación con sujetos infantiles (debido a efectos del amamantamiento, destete y aspectos relacionados con su crecimiento); y (b) inclusión de individuos con fechados, ya sea directo o por termoluminiscencia. El sexo de los individuos fue estimado usando el método de Walrath y colaboradores (2004) para cráneo y de Buikstra y Ubelaker (1994) para coxal. La edad de los mismos también fue estimada utilizando la metodología propuesta por Buikstra y Ubelaker (1994), evaluando centros secundarios de osificación, erupción dental y sínfisis púbica. En el caso de
Solcor 3, se descartaron seis muestras debido a la mala preservación de su colágeno (Ambrose 1990), lo que se aplica igualmente a otras cinco muestras de Coyo 3.

Ya que los datos obtenidos son independientes y todavía no contamos con la suficiente documentación que los vincule, sobre todo por los complejos procesos de formación de los contextos funerarios de San Pedro, la información resultante fue integrada cualitativamente en la discusión final, sin la pretensión de comprobar nuestros supuestos, sino de plantear una interpretación más satisfactoria respecto de las sociedades del pasado.

\section{Nuestra caracterización de la cerámica de San Pedro Negra Pulida (SNP)}

Según nuestro análisis, hemos confirmado la existencia de una tradición cerámica local caracterizada por la manufactura de vasijas no restringidas y restringidas, y representada por el tipo San Pedro Negro Pulido o SNP como la industria predominante. Los atributos de sus pastas son mayoritariamente graníticos y volcánicos, fácilmente reconocibles por sus abundantes inclusiones de cuarzo, además de otras; las que fueron preparadas de diversas maneras debido a distintos grados de homogeneidad y vitrificación, lo compacto o no de ellas y la mayor o menor presencia de antiplástico blanco, negro y/o mica (Echenique 2011; Tarragó 1976). A esto se suma el empleo de técnicas que, de acuerdo con la morfología de las vasijas, privilegiaron el enrollamiento y el ahuecamiento, hasta el uso de placas y la unión de cuerpos en los especímenes más complejos. Paralelamente, cierta variación en torno a estas características nos permite suponer más de una manera de hacer alfarería y más de un grupo o unidades que reprodujeron un mismo estilo.

Dentro del tipo San Pedro Negro Pulido (Figura 3) hemos diferenciado dos conjuntos de formas presentes en los contextos funerarios (Tarragó 1989). Por un lado, cuencos con y sin asas (SNP-4, Figura 3d-f) asociados a botellas con o sin rostros modelados (SNP-6, Figura 3g-j); mientras que por otro lado, es común que se agrupen escudillas con o sin asas (SNP-2, Figura 2b), vasos con asas (SNP-1, Figura 3a) y tazones (SNP-3, Figura 3c). La frecuencia de los cuencos varía entre 24,8 y $34 \%$ en los casos de Solcor y Coyo, respectivamente; las escudillas entre 21,8 y $28,6 \%$, los vasos entre 6,8 y $13 \%$, los tazones entre 3,4 y $6,8 \%$ y, finalmente, 
b
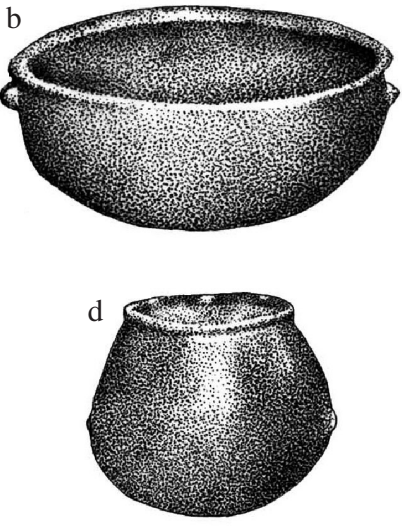

a

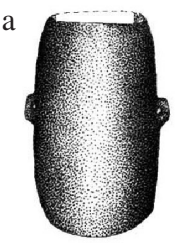

C
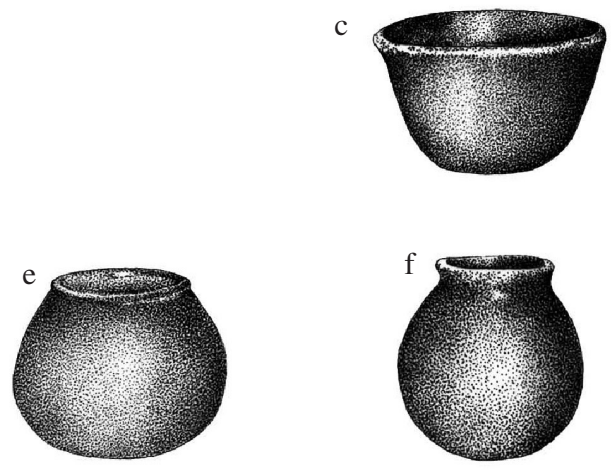
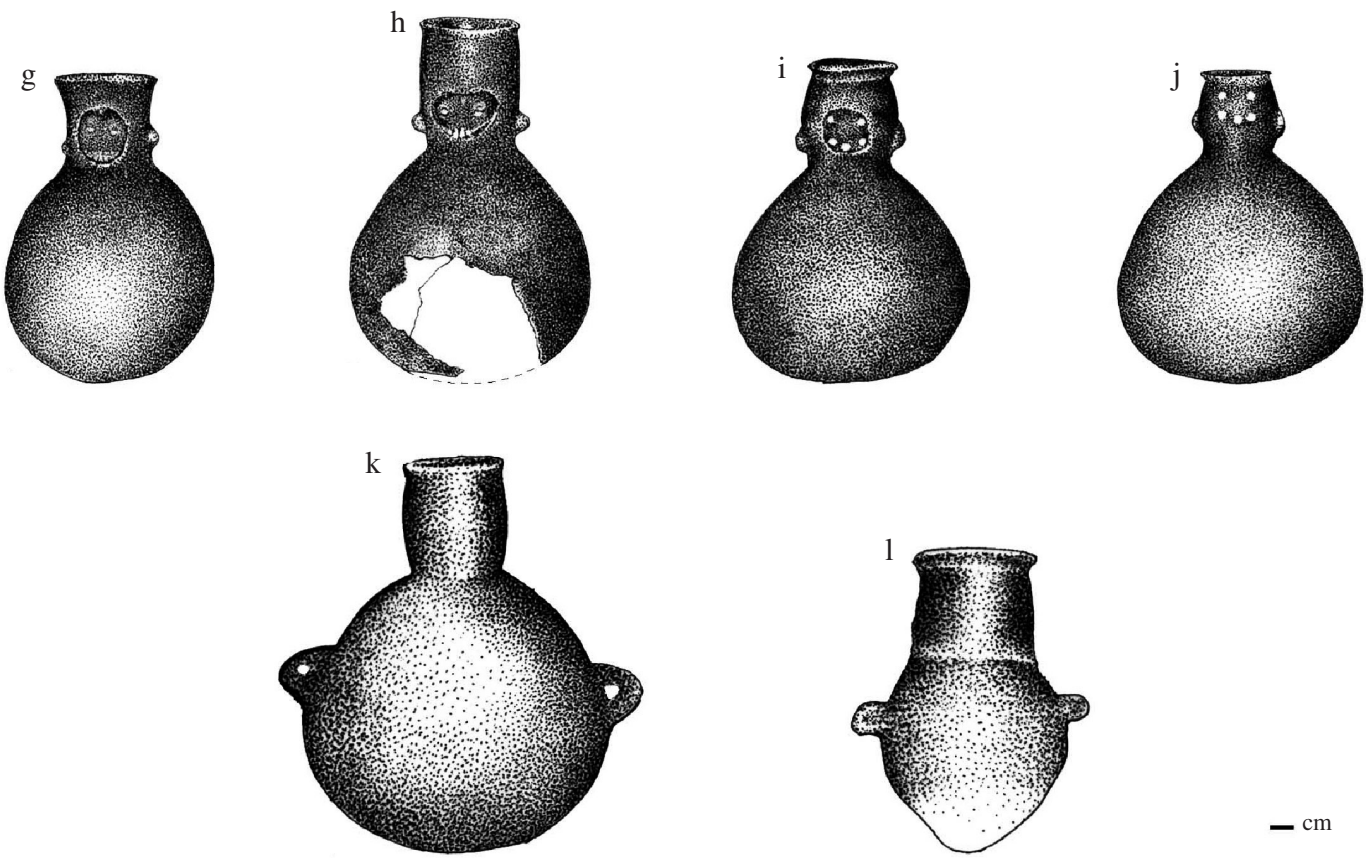

$-\mathrm{cm}$

Figura 3. Tipos Cerámicos San Pedro Negro Pulido: (a-c) vasijas no-restringidas (vaso SNP-1, escudilla SPN-2 y tazón SNP-3); (d-f) vasijas restringidas simples (cuencos con y sin asas SNP-4); (g-1) vasijas restringidas independientes (botellas SNP-6 y cántaros SNP-7). (Fuente: Uribe 2004).

San Pedro Polished Black Ware: (a-c) irrestricted vessels (SNP-1 cup, SNP-2 deep bowl and SNP-3 large cup); (d-f) simple restricted vessels (SNP-4 bowls with and without handles); ( $g-l$ ) independent restricted vessels (SNP-6 bottles and SNP-7 pitchers). (From: Uribe 2004). 
las botellas entre 0,6 y $12,6 \%$ en cada sitio. Por lo tanto, las vasijas más frecuentes serían los cuencos, seguidos por las escudillas, después por los vasos $\mathrm{y}$, por último, las botellas y tazones, quedando atrás una serie más variada y poco frecuente de cántaros, ollas y tazas (Figura 3k-1).

En general se trata de piezas de tamaño mediano (altura promedio de $11 \mathrm{~cm}$ ), salvo por las vasijas menos comunes como los cántaros que muchas veces son muy grandes (hasta $23 \mathrm{~cm}$ ) y de paredes más gruesas; mientras las ollas y tazas casi siempre corresponden a miniaturas (desde $4 \mathrm{~cm}$ ). Por otra parte, es imposible discriminar de manera absoluta la existencia de piezas que tipologías previas han clasificado como cerámica "gruesa" (Tarragó 1989); pues si bien las vasijas presentan un espesor promedio de $5 \mathrm{~mm}$, este puede variar bastante dentro de una misma forma en razón, seguramente, de la maestría del artesano, la función del objeto y las contingencias que afectaron su manufactura.

En todas ellas es normativo el acabado negro y pulido de las superficies (Munsell Soil Color Chart Gley $13 / \mathrm{N}$, Gley $12.5 / \mathrm{N}$, Gley $14 / \mathrm{N}, .5 Y R$ 3/1, 10YR 2/1), logrado por la aplicación de algún revestimiento y/o cocción reductora, abarcando ambas caras de las vasijas irrestrictas y principalmente el exterior de las piezas restringidas. Tampoco es posible diferenciar en forma tajante la existencia de un tipo "gris casi pulido"; ya que se trata de las mismas vasijas negras pulidas, pero que por condiciones de cocción u otras variables de la manufactura no lograron el tratamiento deseado y quedaron grises, marrones, e incluso rojas, debido a la aplicación de un revestimiento que incluyó óxidos de hierro como hematita (especularita) y quizás bórax como aglutinante (Tarragó 1976). Asimismo, el pulido no siempre fue igualmente intenso, tampoco parejo según las partes de las piezas, ni hecho con el mismo instrumento, por lo que más bien existe una gradiente entre el bruñido y lo casi pulido. En suma, dentro de una escala cromática donde intencionadamente predomina el negro, también existe un continuo que incluye las tonalidades grises y rojas, más o menos pulidas y que no constituyen tipos distintos (Tarragó 1989). Todo lo anterior también ha sido reconocido en los materiales domésticos y residenciales (Echenique 2011).

La decoración modelada y pintada resultan ser un hecho bastante excepcional, casi siempre vinculadas a los tipos engobados e incisos, reafirmando su carácter especial. En el caso del San Pedro Negro
Pulido, aparte de algunas asas de morfología irregular a modo de "orejas" o figuras zoomorfas, esta decoración se circunscribe principalmente a rostros modelados más o menos naturalistas y en general abstractos (hechos a base de cuatro o cinco agujeros o puntos que insinúan ojos, nariz y boca), equivalentes a la decoración B definida por Tarragó $(1976,1989)$. En su mayoría, estos modelados fueron aplicados en el cuello de las botellas (Figura 3g-j), aunque también se registran en unos pocos cuencos. En el caso de Solcor 3 representan el 21,4\% de la colección, donde más del $45 \%$ corresponde a rostros antropomorfos frontales, abstractos y dobles; a los que se suman casi $10 \%$ de rostros más realistas o esquemáticos y solo $2 \%$ propiamente naturalistas. El resto se trata de los incisos que comprenden achurados, cuadriculados, punteados, rombos y/o figuras curvas con aspecto de espirales, a veces combinados en el mismo diseño (Figura 4a). Este último icono tradicionalmente se ha denominado "juego de cola" (Figura 4b), pues se vincula con representaciones zoomorfas, posiblemente camélidos, las que también aparecen en otras colecciones con un carácter más naturalista e incluso asociado a imágenes antropomorfas (Le Paige 1964).

Dentro de estas expresiones decorativas del negro pulido, una acotada cantidad de casos incorpora: (a) decoración incisa con un relleno blanco; (b) aplicación de pintura roja; y/o (c) una policromía en negro y rojo. Lo anterior permite segregar un subtipo mixto mitad rojo-mitad negro o NRP (Figura 4a-b), otro Rojo y/o Negro Pulido Inciso con relleno blanco conocido como cerámica Coyo o COY (Figura 4c-d) y, de manera excepcional, un ejemplar Negro sobre Rojo con modelado o NRP Modelado (Munizaga 1963). En el caso de las vasijas negras o rojas pulidas incisas del tipo Coyo las frecuencias varían de 0,8 a 1,3\% en Solcor y Coyo, respectivamente; de 1,2 a $2,5 \%$ las piezas mixtas negras-rojas (NRP) y alrededor de $0,8 \%$ los ejemplares mixtos e incisos en cada sitio. $\mathrm{Su}$ decoración así como su escasa presencia sugieren que se trata de piezas exclusivas en comparación con las negras pulidas tradicionales.

Por último, en un vaso con asa de Solcor 3 se reconoce el único ejemplar propiamente pintado hasta ahora, el cual muestra un diseño con figuras geométricas en negro sobre rojo que recuerdan al estilo Tiwanaku, pero cuya manufactura es de indudable elaboración local. Sin duda se trata de una pieza excepcional, ya que además 


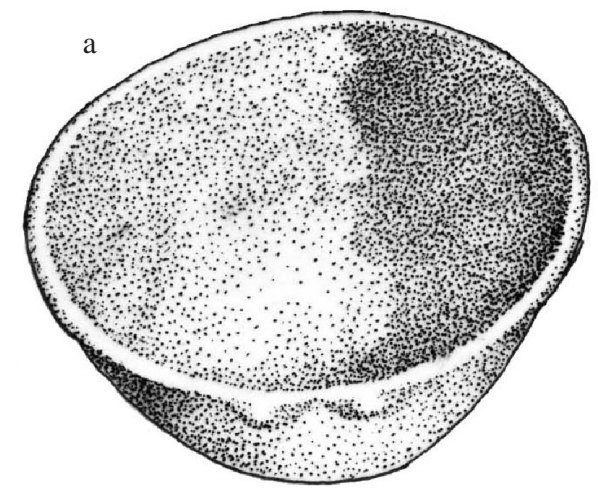

b

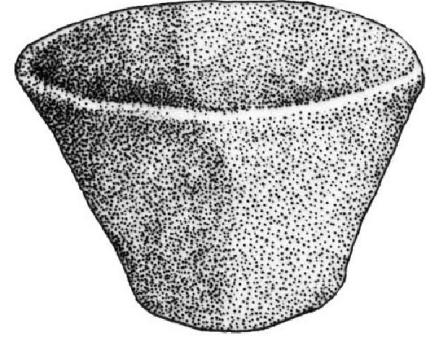

c

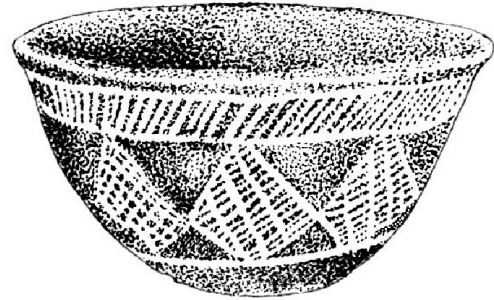

d

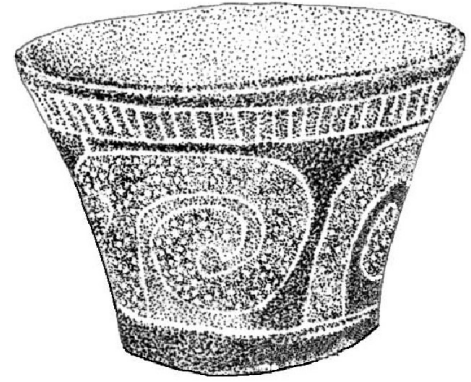

- $\mathrm{cm}$

Figura 4. Tipos Cerámicos San Pedro Mixto e Inciso: a-b) vasijas no-restringidas mixtas mitad negro-mitad rojo o NRP (tazón); c-d) vasijas no-restringidas incisas con relleno blanco del tipo Coyo o COY (Fuente: Uribe 2004).

San Pedro Mix and Incised Ware: ( $a$-b) black and red irrestricted mix vessels or NRP (large cup); $(c-d)$ incised with white pigment irrestricted Coyo vessels or COY (From: Uribe 2004).

integra un modelado naturalista sobre el asa con el aspecto de camélido mitad rojo-mitad negro. Quizás es la única y más exclusiva manifestación de la alfarería sanpedrina que incorporaría elementos estilísticos propios del Horizonte Medio. Complementariamente, otras expresiones cerámicas diferentes por su estilo, técnicas y escaso número son claramente asignables a tradiciones foráneas, cuya presencia no representa más allá del 0,8 al 1,8\%, al menos en Solcor y Coyo. Por lo tanto, se concluye una mínima presencia o influencia externa, no obstante, son recurrentes los ejemplares de los Valles Orientales, el Altiplano Meridional de Bolivia y Noroeste Argentino (Thomas et al. 1984), con lo cual se pudo producir la conexión con el Titicaca. En Solcor 3 fue posible identificar solo una pieza propiamente
Tiwanaku (vaso-quero), la que apenas representa el $0,4 \%$ de la colección (Figura 5a); mientras que los ejemplares del Altiplano Meridional (Oruro y Potosí), específicamente Yura-Uruquilla y/o Chichas (Figura 5b-d), no superan el 1,8\% como ocurre en Coyo Oriente. Estas cerámicas se caracterizan por una decoración policroma, así como por atributos distintivos de pasta, morfología y técnicas de manufactura en general. Respecto de los casos del Altiplano Meridional destaca el uso de pintura blanca o ante, negra y/o roja (Fernández 1978; Tarragó 1989), con las cuales se realizaron finos diseños sobre tazones y jarros, donde predominan figuras geométricas de motivos triangulares, a veces complementados con modelados naturalistas de rostros antropomorfos en jarros o vasos. Esto es coincidente con lo registrado en otros cementerios; 


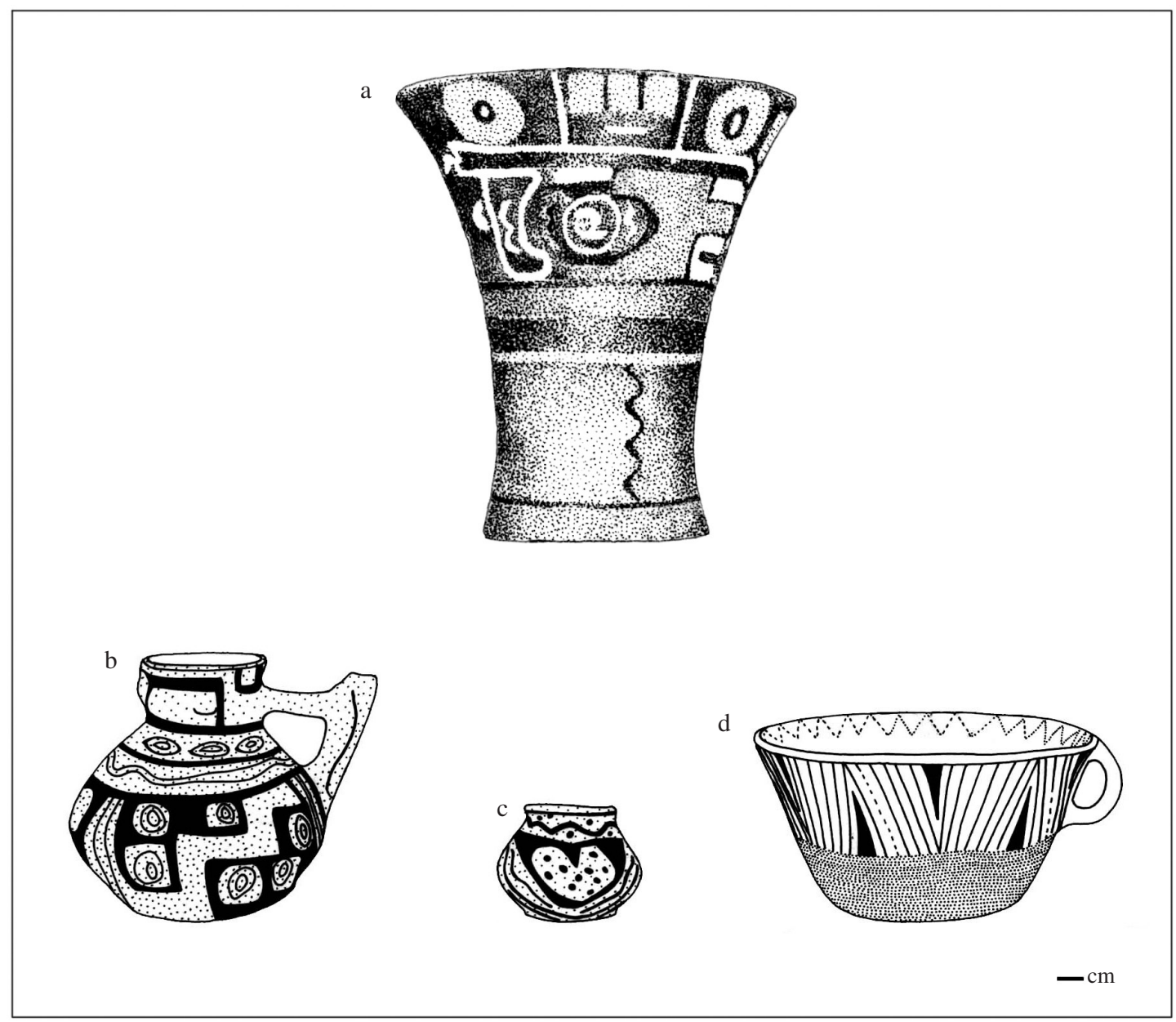

Figura 5. Tipos Cerámicos Foráneos del Altiplano Meridional: (a) vasijas no-restringidas policromas Tiwanaku (vaso-quero); (b-c) vasijas restringidas policromas Yura-Uruquilla (jarro y cuenco miniatura); (d) vasijas no-restringidas policromas Chichas (tazón). (Fuente: Uribe 2004).

Southern Altiplano Foreign Wares: (a) polychrome irrestricted Tiwanaku vessels (quero-cup); (b-(c) polychrome restricted Yura-Uruquilla vessels (jar and miniature bowl); (d) polychrome irrestricted Chichas vessels (large cup). (From: Uribe 2004).

por ejemplo, la presencia de un jarro miniatura Omereque (Tchilimoya-4866[8051]), además de otras piezas Mojocoya y Tupuraya (Tarragó 1989), todos los cuales refieren a conexiones con Cochabamba, e indirectamente con Tiwanaku.

\section{Alcances temporales y contextuales de la cerámica de Solcor y Coyo}

Dentro de un marco temporal amplio, las ocupaciones de Solcor y Coyo asociadas a esta tradición no se restringen al período Medio, sino que habrían comenzado en algún momento del Formativo, coincidente con la fase Sequitor, extendiéndose hasta los inicios del Intermedio Tardío o fase
Yaye-Solor (Berenguer et al. 1986; Llagostera et al. 1988; Tarragó 1989). Sin embargo, concordamos con las recientes propuestas cronológicas (TorresRouff y Hubbe 2013) que afirman que el clímax ocupacional se desarrolló en el período Medio (400-1.000 d.C.) y, de acuerdo con las fechas por termoluminiscencia disponibles, durante los años 510 y 920 d.C., involucrando las fases Quitor y Coyo del período en cuestión (Berenguer et al. 1986). Debido al predominio de la cerámica negra pulida clásica, en definitiva, se confirma que gran parte de la ocupación de estos sitios se acotó a este momento, pero donde la cerámica Tiwanaku o altiplánica habría sido muy reducida, particular y/o selectiva (Figura 6a-b). 
a

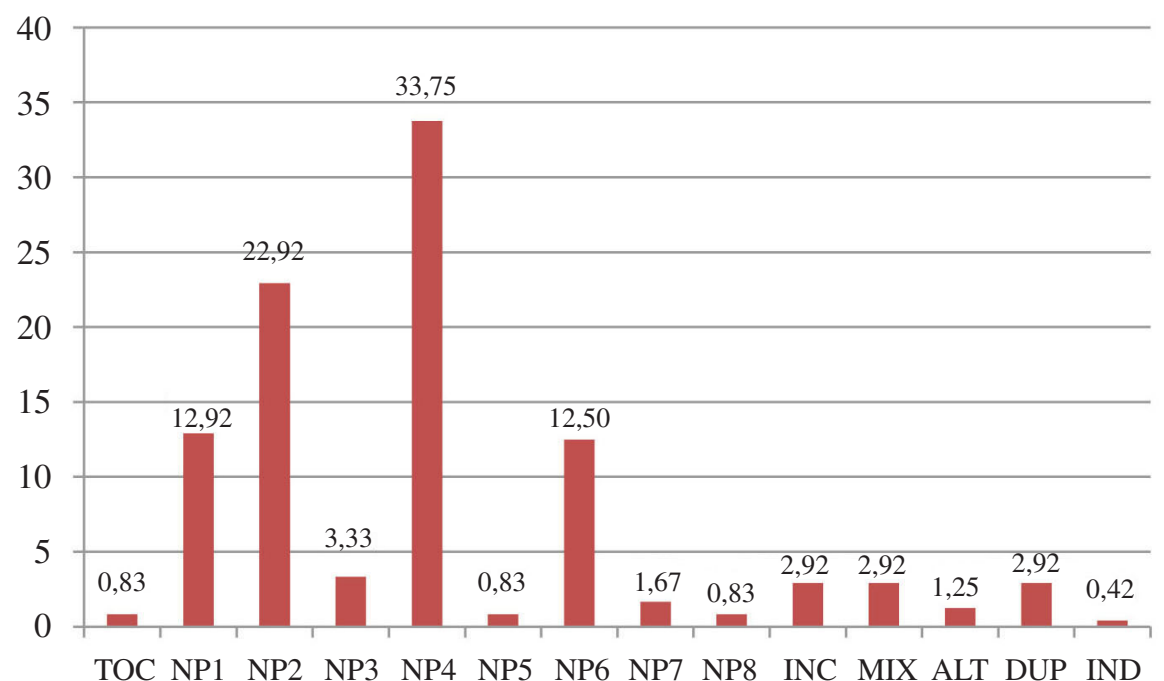

b

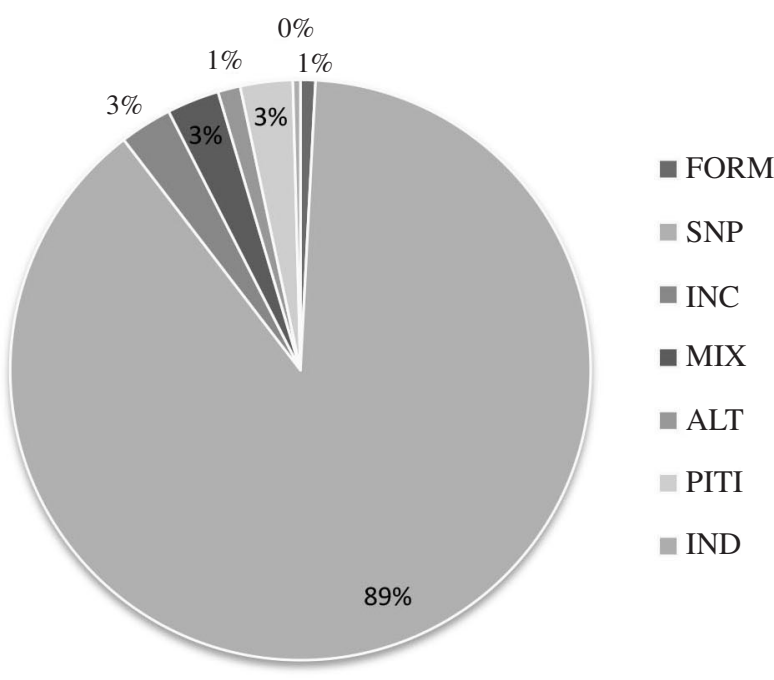

Figura 6. Gráficos de frecuencias relativas de la cerámica analizada (\% cantidad de piezas completas): (a) frecuencia por tipos cerámicos (TOC: período Formativo; NP1-NP8, INC [COY] y MIX: período Medio; ALT: Altiplánica Tiwanaku y derivados; DUP: período Intermedio Tardío; IND: Indeterminado; (b) frecuencia por componentes o tradiciones cerámicas (período Formativo; SNP: San Pedro Negro Pulida; INC: San Pedro Incisa o Coyo (COY); MIX: San Pedro Mixta (Negra-Roja); ALT: Altiplánica Tiwanaku y derivados; PITI: período Intermedio Tardío; IND: Indeterminada).

Graphs of relative ceramic frequencies (percent of complete vessels): (a) ceramic type frequencies (TOC: Formative Period; NP1NP8, INC [COY] y MIX: Middle Period; ALT: Tiwanaku and related Altiplano ceramics; DUP: Late Intermediate Period; IND: Unknown; (b) ceramic traditions frequencies (Form: Formative Period; SNP: San Pedro Black Polished Ware; INC: San Pedro Incised Ware or Coyo (COY); MIX: San Pedro Mix Ware (Black-Red); ALT: Tiwanaku and related Altiplano ceramics; PITI: Late Intermediate Period; IND: Unknown).

En consecuencia, en este lapso es posible confirmar el apogeo de una industria alfarera local con gran valor identitario (Stovel 2005). La alfarería negra pulida seguramente fue producida por más de un grupo o taller, pero cumplió con normas muy rígidas de estilo como lo evidencia su moderada variabilidad interna, constituyéndose en una manufactura bastante estandarizada y culturalmente unitaria. La mayoría de las piezas estuvo destinada a satisfacer un número específico de funciones para contener, presentar y servir, en el ámbito ceremonial y cotidiano, debido a la presencia de huellas de uso 
en más de la mitad de ellas. Por lo tanto, el tipo San Pedro Negro Pulido estaría vinculando estrecha y simbólicamente ambos mundos, el de los vivos y el de los muertos.

De acuerdo con nuestros registros, solo la cerámica negra pulida representaría más del $90 \%$ de la muestra de cementerios de San Pedro de Atacama, alcanzando frecuencias no menores al $69,4 \%$ y hasta $89 \%$ en lugares como Coyo y Solcor (Figura 6a-b). Dentro de esta producción masiva se habría dejado un segmento menor de vasijas más infrecuentes y reducidas en su circulación. Por lo tanto, la dinámica local y el manejo de su cultura material parecieran haber tenido un significado más determinante que la mera existencia de distinciones cronológicas o de agentes externos, apoyándose en la marcada identidad estilística de su cerámica sobria y oscura y un riguroso ritual funerario. Por su presencia, cantidad y variedad, entonces, es posible pensar que las diferencias de composición en las sepulturas podrían tener consecuencias sociales, apoyando planteamientos más recientes (Stovel 2001; Torres-Rouff y Hubbe 2013).

De este modo, tanto cuencos como escudillas negras pulidas (SNP-4 y SNP-2) se encontrarían en más de la mitad de las tumbas, pues en su conjunto comprenden el 53,4 y 55,8\% de las colecciones de Solcor y Coyo, constituyendo las piezas y asociaciones dominantes que dan cuenta de la intensidad ocupacional del período Medio. Por consiguiente, en general la población fue enterrada con cuencos y escudillas, además de vasos (SNP1), tazones (SNP-3) y/o botellas (SNP-6), solos o juntos, constituyendo los conjuntos cerámicos más comunes durante la vigencia de cada cementerio (Figura 6a-b). Paralelamente se manifiesta un pequeño conjunto cerámico cuyos ejemplares marcarían diferencias temporales y sociales entre las tumbas y sus portadores, compuesto tanto por cerámica foránea como por ciertos ejemplares de la misma tradición negra pulida que nos interesa destacar (Figura 6a-b). Relacionado con lo anterior y revisando la información contextual, se pudo determinar que de un promedio de casi tres vasijas por tumba, existirían sepulturas con poca (hasta tres piezas) y mucha cerámica (más de cinco); configurándose como un grupo mayoritario aquellas tumbas con pocas piezas y otro mucho más restringido pero abundante en cerámica, aparte de los casos sin cerámica que formarían una tercera categoría.
En términos de asociaciones, por lo tanto, los individuos fueron ofrendados con cuencos y escudillas y/o con vasos y botellas por un lado; mientras que por otro, una proporción menor pero recurrente lo hizo con cuencos, escudillas, botellas y otras piezas singulares. Es decir, en la menor cantidad de tumbas aparece una mayor diversidad de vasijas negras pulidas, al mismo tiempo que se integrarían los tipos mixtos, incisos y rojos y/o los ejemplares foráneos del periodo, incluso botellas tempranas del tipo Toconao o escudillas tardías del tipo Dupont (Figura 6a-b). Esto es evidente en las tumbas con más de siete vasijas, del todo escasas, pero donde justamente se concentran aquellos tipos incisos, rojos y mixtos. No obstante, también algunos contextos menos abundantes destacan dentro del promedio (p.ej., con una sola pieza), porque solo poseen esta clase de piezas más exclusivas. En suma, se trataría de los especímenes menos frecuentes como los modelados, incisos, rojos y mixtos antes descritos, siendo especialmente las tumbas con mayor cantidad y cierta calidad de ofrendas las que monopolizan estas piezas. Estas, además, estarían limitadas a un grupo menor de la población sepultada en los cementerios, sugiriendo diferencias sociales al interior de cada comunidad. Por ejemplo, de 39 tumbas $(33,33 \%)$ bien documentadas de Solcor 3 $(\mathrm{n}=117)$, seis incluyen este conjunto cerámico $(15,38 \%)$, todas asociadas a elementos del complejo alucinógeno de estilo Tiwanaku o equivalente, posibles de asignar a siete hombres, la mayoría sin deformación (apenas dos deformados), solo a dos mujeres (una con deformación) y a un infante (Horta 2014; Llagostera et al. 1988).

En consecuencia, dentro de la identidad estilística dominante, es evidente que el patrón de ofrendas cerámicas fue mayormente heterogéneo y desigual. Dejando de lado las diferencias cronológicas, este pequeño grupo de tumbas se relacionaría con el conjunto de piezas de la tradición negra pulida que marca la diferencia entre las sepulturas, aludiendo a casos especiales o exclusivos temporal, identitaria y/o socialmente hablando. La población enterrada, entonces, podría dividirse en segmentos. Coincidiendo con interpretaciones anteriores, esta situación aludiría a condiciones de acumulación, a conexiones a larga distancia y vínculos con grupos lejanos por parte de algunos individuos de San Pedro. Este grupo, reiteramos, es muy probable que fuera el que se distinguió por sus contactos extranjeros (reales o ficticios) como pudo ser con 
Tiwanaku o, mejor dicho, con distintas entidades del Altiplano, la Circumpuna e incluso los Valles Orientales de Bolivia.

Más allá del debate cronológico en cuestión (Torres-Rouff y Hubbe 2013), por lo tanto, proponemos que durante este período se habría desarrollado un paralelismo social en San Pedro, lapso durante el cual se mantuvo el apogeo de la producción cerámica negra pulida. Dicho paralelismo se habría expresado en la existencia de los pequeños segmentos de la población que, frente a la mayoría, se enterraron con una expresión más variada y exclusiva de esta alfarería. Incluso, nos parece que, sobre todo en la denominada fase Coyo (750-1.000 d.C.), se radicalizaron las diferencias al interior de la sociedad local, lo cual tradicionalmente se ha adscrito a la intensificación del contacto externo porque se concentrarían más ejemplares Tiwanaku y foráneos en los oasis (Llagostera 1996; Llagostera et al. 1988; Núñez 1992). No obstante, a nuestro juicio, esta situación no habría significado un quiebre en la aparente unidad atacameña provocado por los agentes externos de Tiwanaku como plantean aquellos autores. $\mathrm{Al}$ contrario, pareciera que las comunidades locales convergieron con mayor fuerza en torno a los oasis sanpedrinos como si todas asumieran, al menos en apariencia, un proyecto compartido pero ejecutado de manera autónoma en cada caso particular. Este, sin embargo, paradójicamente alcanzaría su apogeo para colapsar de manera abrupta y dar paso a una nueva situación en el Intermedio Tardío.

\section{Nuevos análisis de isótopos estables $\delta^{13} \mathrm{C}$ y $\delta^{15} \mathrm{~N}$ para Solcor y Coyo}

Sin todavía conocer bien qué pasaba en el ámbito cotidiano (Stovel 1997), los antecedentes y nuestro análisis de la cerámica funeraria que establece la existencia de un estilo homogeneizador pero con una distribución diferenciada, sugieren que al interior de la población local existían contradicciones internas y notorias tensiones, probablemente relacionadas con una considerable jerarquización y desigualdad social. Esta situación la comparamos con otros datos bioarqueológicos que discutimos a continuación. De este modo, proporcionamos nueva evidencia relativa a la dieta y movilidad de los cementerios Solcor 3 (154 tumbas) y Coyo 3 (51 tumbas), provista por nuestras actuales investigaciones.

Los valores de $\delta^{13} \mathrm{C}$ y $\delta^{15} \mathrm{~N}$ obtenidos a partir de la fracción orgánica del hueso (colágeno) son presentados en la Tabla 1 y puede observarse que en ambos cementerios hubo un consumo de dieta preferentemente terrestre (Figuras 7 y 8), incluyendo también la ingesta de plantas $\mathrm{C}_{4}$ (en este caso maíz) y $\mathrm{C}_{3}$ (plantas silvestres y otros cultivos tales como porotos, zapallo, etc.). Sin embargo, también se aprecia con claridad que los valores de $\delta^{15} \mathrm{~N}$ resultaron especialmente más elevados en Coyo 3 que en Solcor 3 ( $t$ test, $p=0,00001$ ), lo que podría estar evidenciando un mayor consumo de proteínas terrestres en el caso de Coyo 3 . Los estudios de poblaciones costeras del norte de Chile han demostrado que la dieta marina eleva los valores de $\delta^{15} \mathrm{~N}$ sobre 14\%o (Roberts et al. 2013; Santana et al. 2012, 2014; Tieszen et al. 1992), pero es muy poco probable el consumo de recursos costeros en los oasis de San Pedro. Lo que se condice con la casi absoluta ausencia de evidencias marinas en el registro de la localidad. Por lo tanto, es necesario considerar la influencia de otros factores que pudieran estar elevando los valores de nitrógeno en Coyo 3 como, por ejemplo, el consumo de carne de alpaca. Esta, según se ha demostrado, posee valores de $\delta^{15} \mathrm{~N}$ más altos que otros herbívoros, incluyendo las llamas, debido a su particular fisiología intestinal (Sponheimer et al. 2003). Complementariamente, análisis de isótopos estables en llamas y guanacos de Tulán 54, al sur de San Pedro, han evidenciado que sus valores de nitrógeno pueden ascender hasta 13\%o (López et al. 2013), posiblemente debido a su adaptación a ambientes desérticos y al efecto de la aridez (Ambrose 1991). Asimismo, el uso de fertilizantes agrícolas, como el guano de llama, también pudieron tener un efecto en los altos valores de nitrógeno de las plantas cultivadas (Finucane 2006; Szpak et al. 2012).

Paralelamente, al comparar de forma intergrupal los cementerios de Solcor 3 y Coyo 3 es posible observar más diferencias significativas (Figuras 7 y 8), tanto en los valores de $\delta^{13} \mathrm{C}$ obtenidos del colágeno como de la apatita del hueso $\left(\delta^{13} \mathrm{C}_{\text {colágeno' }}\right.$, $\mathrm{t}$ test, $\mathrm{p}=0,0048 ; \delta^{13} \mathrm{C}_{\text {apatita }}$, t test, $\left.\mathrm{p}=0,023\right)$. En ambas colecciones se evidenció consumo de maíz; no obstante, Coyo 3 de nuevo destaca por una mayor ingesta de tales recursos en comparación con Solcor 3. No obstante estas diferencias entre cementerios, al momento de comparar los valores de carbono a nivel intra poblacional se detectó una considerable variabilidad en el consumo de maíz tanto en Coyo como en Solcor. En efecto, es posible que: (a) parte de los individuos basara su dieta en un consumo mayor de plantas $C_{3}$ (p.ej., Solcor 3 presenta un 
Tabla 1. Valores isotópicos de $\delta^{3} \mathrm{C}_{\text {colágeno }}, \delta^{13} \mathrm{C}_{\text {apatita }}$, y $\delta^{18} \mathrm{O}$ para individuos de los cementerios Solcor 3 y Coyo 3 por sexo y edad. También se presentan las razones de Carbono/Nitrógeno. Los valores de razón de $\mathrm{C} / \mathrm{N}$ que se encuentran fuera del rango aceptado para buena preservación de colágeno se muestran en cursivas. Isotopic values of $\delta^{13} C_{\text {collagen, }}, \delta^{13} C_{\text {apatite }}$ and $\delta^{18} O$ for the Solcor 3 and Coyo 3 individuals by sex and age.

Carbon/Nitrogen ratios are also shown in the table. Values that fall outside the range expected for good collagen preservation are presented in italics.

\begin{tabular}{|c|c|c|c|c|c|c|c|c|c|}
\hline Sitio & Tumba & Cuerpo & Sexo & Muestra & $\delta^{15} \mathrm{~N}_{\mathrm{AIR}}$ & $\delta^{13} \mathrm{Ccol}_{\mathrm{VPDB}}$ & $\delta^{13} \mathrm{Cap}$ VPDB & $\delta^{18} \mathrm{O}_{\mathrm{VPDB}}$ & $\mathrm{C} / \mathrm{N}$ \\
\hline \multirow{22}{*}{ Coyo 3} & 1 & 13208 & $\mathrm{~F}$ & $11^{\circ}$ costilla izquierda & 12,6 & $-15,1$ & $-6,9$ & $-0,4$ & 3,5 \\
\hline & 2 & 13219 & M & $12^{\circ}$ costilla derecha & - & - & $-8,5$ & $-2,3$ & 3,7 \\
\hline & 3 & 13223 & M & 9-10 costilla izquierda & 12,8 & $-13,1$ & $-7,9$ & $-3,7$ & 3,2 \\
\hline & 5 & 13280 & F & $12^{\circ}$ costilla izquierda & 12,8 & $-14,7$ & $-7,2$ & $-3,8$ & 3,4 \\
\hline & 7 & 13228 & $\mathrm{~F}$ & $12^{\circ}$ costilla derecha & 12,4 & $-17,4$ & $-9,5$ & $-3,4$ & 3,6 \\
\hline & 8 & 13236 & $\mathrm{~F}$ & $8^{\circ}$ costilla derecha & - & - & $-8,2$ & $-5,9$ & 4,2 \\
\hline & 15 & 13276 & M & Fragmento costilla derecha & 11,9 & $-14,0$ & $-9,5$ & $-4,3$ & 3,3 \\
\hline & 16 & 13291 & $\mathrm{~F}$ & $12^{\circ}$ costilla derecha & 13,5 & $-13,6$ & $-6,7$ & 1,4 & 3,4 \\
\hline & 17 & 13285 & M & $12^{\circ}$ costilla izquierda & 11,3 & $-17,5$ & $-9,3$ & $-1,1$ & 3,4 \\
\hline & 17 & 13286 & M & 6-9 costilla derecha & 12,4 & $-13,3$ & $-8,9$ & $-4,0$ & 3,2 \\
\hline & 19 & 13325 & M & $11^{\circ}$ costilla izquierda & - & - & $-7,7$ & $-2,0$ & 3,9 \\
\hline & 21 & 13335 & M & $11^{\circ}$ costilla izquierda & 11,3 & $-12,2$ & $-6,3$ & $-3,6$ & 3,2 \\
\hline & 22 & 13315 & F & $12^{\circ}$ costilla izquierda & 13,9 & $-14,6$ & $-7,1$ & $-2,8$ & 3,4 \\
\hline & 26 & 13350 & $\mathrm{~F}$ & $12^{\circ}$ costilla derecha & 12,0 & $-12,8$ & $-8,9$ & $-5,0$ & 3,2 \\
\hline & 27 & 13348 & M & $12^{\circ}$ costilla izquierda & 11,7 & $-13,2$ & $-7,3$ & $-3,7$ & 3,2 \\
\hline & 41 & 13679 & $\mathrm{~F}$ & Falange proximal mano & 11,3 & $-25,5$ & $-9,5$ & 0,7 & 5,2 \\
\hline & 44 & 13708 & F & $7^{\circ}$ costilla derecha & - & - & $-10,1$ & $-5,6$ & - \\
\hline & 44 & 13715 & F & $8^{\circ}$ costilla izquierda & 13,1 & $-14,4$ & $-9,9$ & $-4,0$ & 3,3 \\
\hline & 45 & 13736 & M & $8^{\circ}-10^{\circ}$ costilla derecha & 12,0 & $-14,2$ & $-9,7$ & $-4,1$ & 3,4 \\
\hline & 47 & 13756 & M & $11^{\circ}$ costilla derecha & 10,5 & $-15,4$ & $-10,7$ & $-4,7$ & 3,3 \\
\hline & 48 & 13761 & I & $6^{\circ}$ costilla izquierda & 12,2 & $-14,4$ & $-9,6$ & $-4,3$ & 3,2 \\
\hline & 49 & 13774 & I & $8^{\circ}$ costilla izquierda & 11,5 & $-14,1$ & $-8,4$ & $-3,3$ & 3,1 \\
\hline \multirow{30}{*}{ Solcor 3} & 1 & 955 & M & $7^{\circ}$ costilla izquierda & 10,9 & $-15,7$ & $-9,0$ & $-1,0$ & 3,3 \\
\hline & 5 & 1049 & $\mathrm{~F}$ & $12^{\circ}$ costilla izquierda & 11,4 & $-15,9$ & $-8,1$ & $-1,7$ & 3,5 \\
\hline & 6 & 1079 & M & $12^{\circ}$ costilla derecha & - & - & $-9,5$ & $-2,8$ & 2,6 \\
\hline & 6 & 1080 & M & $1^{\circ}$ falange proximal pie & - & - & $-9,4$ & $-1,9$ & 5,1 \\
\hline & 6 & 1078 & $\mathrm{~F}$ & $11^{\circ}$ costilla izquierda & 12,3 & $-14,8$ & $-8,6$ & $-2,7$ & 3,2 \\
\hline & 11 & 1203 & F & $12^{\circ}$ costilla izquierda & - & - & $-10,7$ & $-1,6$ & 4,1 \\
\hline & 12 & 1236 & $\mathrm{~F}$ & $12^{\circ}$ costilla derecha & 11,3 & $-14,8$ & $-8,8$ & $-2,2$ & 3,3 \\
\hline & 14 & 1286 & M & $12^{\circ}$ costilla derecha & - & NA & $-9,4$ & $-0,1$ & 4,1 \\
\hline & 16 & $3062 \mathrm{~A}$ & M & $12^{\circ}$ costilla izquierda & 10,2 & $-17,1$ & $-10,6$ & $-2,2$ & 3,5 \\
\hline & 16 & 3061 & M & $12^{\circ}$ costilla derecha & 11.6 & $-13,9$ & $-7,3$ & $-1,0$ & 3,1 \\
\hline & 16 & 3063 & F & $12^{\circ}$ costilla derecha & 11,0 & $-16,3$ & $-9,5$ & $-2,8$ & 3,5 \\
\hline & 20 & 1455 & $\mathrm{~F}$ & $11^{\circ}$ costilla derecha & 11.6 & $-15,9$ & $-9,8$ & $-0,3$ & 3,3 \\
\hline & 20 & 1456 & $\mathrm{~F}$ & $12^{\circ}$ costilla derecha & 11.8 & $-12,8$ & $-5,7$ & $-3,0$ & 3,3 \\
\hline & 21 & 1516 & M & $12^{\circ}$ costilla izquierda & 10,9 & $-15,4$ & $-10,0$ & $-1,7$ & 3,3 \\
\hline & 24 & 1558 & F & $11^{\circ}$ costilla derecha & 11,6 & $-16,9$ & $-11,2$ & $-1,0$ & 3,2 \\
\hline & 26 & 1592 & $\mathrm{~F}$ & $11^{\circ}$ costilla izquierda & 11,3 & $-16,9$ & $-10,7$ & $-1,2$ & 3,3 \\
\hline & 27 & 1630 & F & $12^{\circ}$ costilla izquierda & 11,4 & $-17,8$ & $-10,9$ & $-2,6$ & 3,4 \\
\hline & 30 & 1683 & M & $12^{\circ}$ costilla derecha & 10,4 & $-16,3$ & $-9,9$ & 0,3 & 3,3 \\
\hline & 31 & 1710 & M & $12^{\circ}$ costilla derecha & 10,6 & $-17,6$ & $-10,6$ & $-3,3$ & 3,5 \\
\hline & 38 & 1791 & M & $12^{\circ}$ costilla derecha & 10,6 & $-14,7$ & $-8,5$ & $-1,7$ & 3,2 \\
\hline & 47 & 1903 & F & $12^{\circ}$ costilla derecha & 11,4 & $-16,6$ & $-10,4$ & $-0,9$ & 3,4 \\
\hline & 52 & 2025 & $\mathrm{~F}$ & Falange proximal mano & - & - & $-10,7$ & 0,8 & 7,9 \\
\hline & 55 & 2113 & $\mathrm{~F}$ & $12^{\circ}$ costilla izquierda & 11,5 & $-15,2$ & $-9,1$ & $-2,6$ & 3,2 \\
\hline & 57 & 2215 & F & $12^{\circ}$ costilla izquierda & 10,3 & $-20,0$ & $-12,1$ & $-0,8$ & 3,5 \\
\hline & 58 & 2269 & M & Costilla derecha & 11,42 & $-13,2$ & $-6,4$ & 0,4 & 3,4 \\
\hline & 59 & 2303 & M & Falange proximal mano & 10,98 & $-14,15$ & $-7,4$ & $-2,5$ & 3,3 \\
\hline & 62 & $2368 \mathrm{~A}$ & M & Falange proximal mano & NA & NA & $-12,0$ & $-2,0$ & 10,8 \\
\hline & 69 & 2475 & M & $12^{\circ}$ costilla izquierda & 10,41 & $-16,31$ & $-9,1$ & 0,1 & 3,4 \\
\hline & 69 & 2476 & $\mathrm{~F}$ & $12^{\circ}$ costilla izquierda & 11,3 & $-15,13$ & $-8,3$ & $-1,9$ & 3,3 \\
\hline & 78 & 2697 & $\mathrm{~F}$ & $11^{\circ}$ costilla izquierda & 11,32 & $-15,46$ & $-9,9$ & $-3,3$ & 3,3 \\
\hline
\end{tabular}




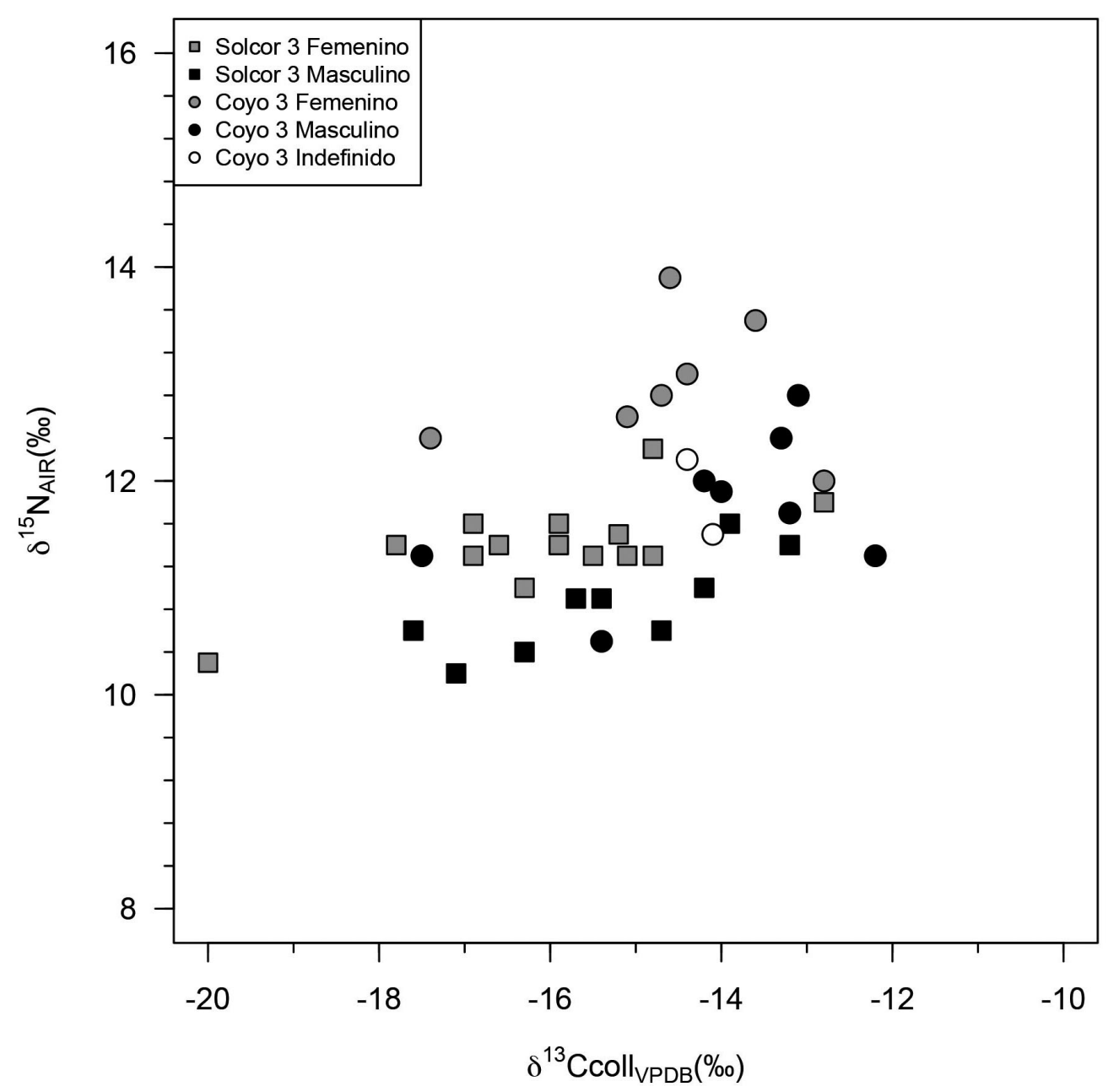

Figura 7. Gráfico de dispersión bivariado con los valores de $\delta^{13} \mathrm{C}_{\text {colágeno }}$ y $\delta^{15} \mathrm{~N}$ para individuos de Solcor 3 y Coyo 3 divididos por sexo.

Bivariate plot showing $\delta^{13} C_{\text {collagen }}$ and $\delta^{15} N$ values for Solcor 3 and Coyo 3 individuals divided by sex.

individuo femenino con valores cercanos a $-20 \%$ o para el $\delta^{13} \mathrm{C}_{\text {colágeno }}$; (b) que otros tuvieran una dieta más bien mixta de plantas $\mathrm{C}_{3}-\mathrm{C}_{4}$; y finalmente; (c) un grupo que consumía mayoritariamente maíz (p.ej., individuos de Coyo 3 que alcanzaron un máximo de $12 \%$ o para el $\delta^{13} \mathrm{C}_{\text {colágeno }}$ ). No obstante, estas diferencias no llegan a ser estadísticamente significativas al ser evaluadas por sexo, aunque sí se observan diferencias relevantes por sexo al comparar los valores de nitrógeno en cada cementerio por separado.

En ambos sitios, por consiguiente, existe una tendencia en la cual las mujeres poseen los valores más enriquecidos en ${ }^{15} \mathrm{~N}$ en comparación a los hombres (Solcor 3, t test, $\mathrm{p}=0,0037$; Coyo 3, t test, $\mathrm{p}=0,0027)$. De este modo, las mujeres serían las que estarían consumiendo una mayor cantidad de proteínas en ambos casos. Cabe recordar que una importante variabilidad en los valores de carbono ya fue observada por Nado et al. (2012) al analizar muestras de apatita del esmalte dental de Solcor 3 y Solcor Plaza, lo que confirma una tendencia a la mayor diversidad dietética en San Pedro de Atacama durante el periodo Medio. Esta variabilidad, además, no solo estaría ocurriendo durante la adultez de los individuos, sino también en su infancia de acuerdo a los anteriores registros isotópicos de esmalte (Nado et al. 2012). En este sentido, la variabilidad observada estaría bastante relacionada con un factor de género y, en consecuencia, también social. 


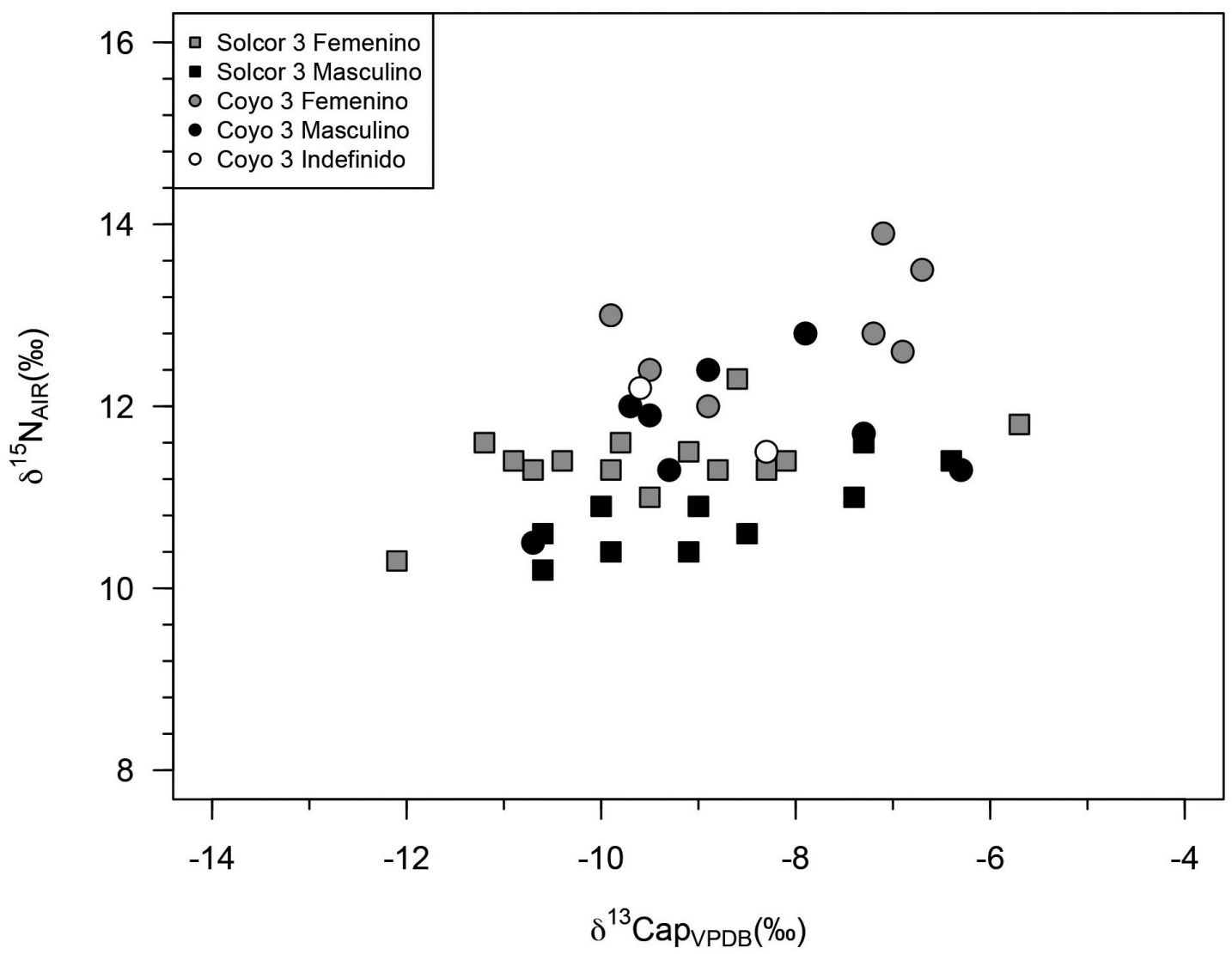

Figura 8. Gráfico de dispersión bivariado con los valores de $\delta^{13} \mathrm{C}_{\text {apatita }}$ y $\delta^{15} \mathrm{~N}$ para individuos de Solcor 3 y Coyo 3 divididos por sexo. Bivariate plot showing $\delta^{13} C_{\text {apatite }}$ and $\delta^{15} N$ values for Solcor 3 and Coyo 3 individuals divided by sex.

En relación con los isótopos de oxígeno utilizados para inferir la movilidad de los individuos, por ingesta de agua durante los últimos años de vida, los resultados de Solcor 3 y Coyo 3 proporcionaron valores que se encuentran dentro del rango esperado para San Pedro, aunque a la par de una gran variabilidad otra vez (Figura 9). En cualquier caso, no fue posible identificar individuos provenientes del altiplano en estas muestras. Los valores de $\delta^{18} \mathrm{O}$ esperados para individuos foráneos y originarios del altiplano, específicamente del Titicaca, se encuentran en un rango entre -10 a -13\%o (Knudson 2009); en cambio, tanto para Solcor 3 como Coyo 3 los valores de isótopos de $\delta^{18} \mathrm{O}$ no caen dentro del rango mencionado (p.ej., - 5,9 a $0,8 \%$ o), lo que sugiere una ausencia de individuos altiplánicos. No se descarta la posibilidad que dentro de la variabilidad de valores para San Pedro existiesen indicadores de individuos originarios de regiones de menor altura, con similares señales de $\delta^{18} \mathrm{O}$. No obstante, tal como
Knudson (2009) y Nado et al. (2012) han destacado, se debe considerar que existe mucha variación en los valores del oxígeno local. Por ejemplo, observamos algunos valores bastante enriquecidos en ${ }^{18} \mathrm{O}$, a veces alcanzando valores sobre $0 \%$, a pesar que los ayllus atacameños se encuentran a unos 2.400 $\mathrm{msm}$. Esto debido seguramente al complejo sistema de aguas que caracteriza al desierto, siendo en este caso que los dos principales ríos de la localidad adquieren sus aguas tanto de las lluvias ocurridas en el verano y por los deshielos además de cursos subterráneos de diferentes fuentes cordilleranas (Aravena 1995; Magaritz et al. 1989; Ortiz et al. 2013). Por otra parte, la variación de los isótopos de oxígeno también depende de las condiciones climáticas del momento, siendo muy afectados por cambios extremos de temperatura y humedad. En efecto, estudios recientes en los ríos Vilama y San Pedro han proporcionado valores isotópicos muy diferentes al ser comparados en un mismo 


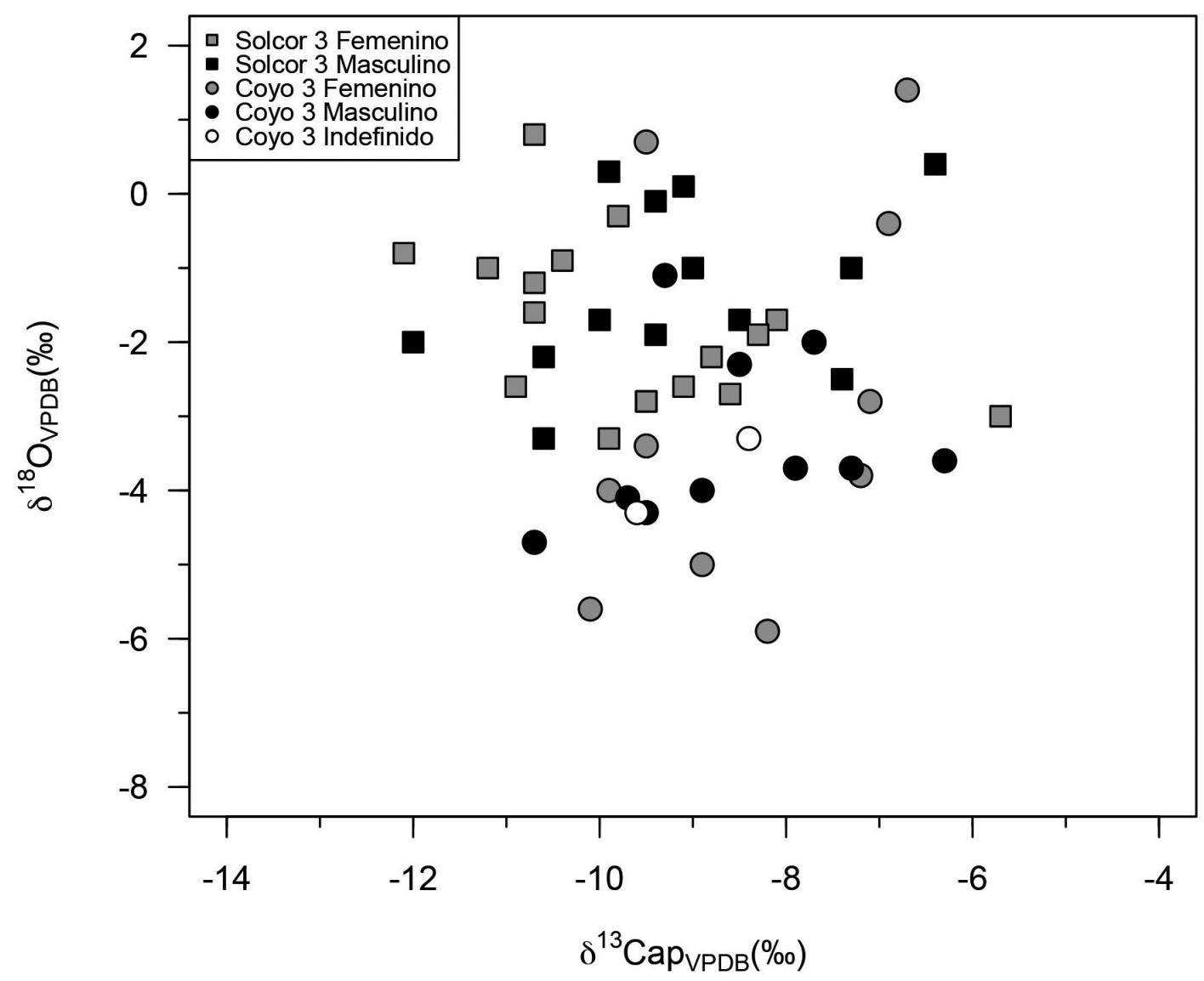

Figura 9. Gráfico de dispersión bivariado con los valores de $\delta^{13} \mathrm{C}_{\text {apatita }}$ y $\delta^{18} \mathrm{O}$ para individuos de Solcor 3 y Coyo 3 divididos por sexo. Bivariate plot showing $\delta^{13} C_{\text {apatite }}$ and $\delta^{18} \mathrm{O}$ values for Solcor 3 and Coyo 3 individuals divided by sex.

período del año, cuyas diferencias pueden alcanzar una variación de hasta 3 a 4\%o (Ramón Aravena comunicación personal 2013).

En síntesis, los resultados de estos nuevos estudios isotópicos confirman un significativo y a la vez variado consumo de maíz y proteína animal terrestre por las poblaciones sanpedrinas de la época. Evidentemente, realizar una generalización sobre tendencias alimenticias y proponer una evolución de la paleodieta local con estos resultados, resulta apresurado. Sin embargo, los datos sí nos permiten cuestionar la hipótesis de una creciente influencia altiplánica en la dieta durante pleno apogeo del período. Nos parece importante destacar que los resultados obtenidos apuntan mejor a la existencia de un amplio repertorio alimentario que ya se encontraba presente en San Pedro. Lo anterior es especialmente relevante para el maíz, pues el aumento del consumo de este recurso $\left(\mathrm{C}_{4}\right)$ implica la disminución relativa de otras plantas $\left(\mathrm{C}_{3}\right)$; por tanto, posibles cultígenos altiplánicos debieron haber mantenido alguna importancia en la dieta sanpedrina, aunque aparentemente muy desplazados.

\section{Para Repensar el Periodo Medio en San Pedro de Atacama}

Este panorama que nos ofrecen la cerámica y los datos bioarqueológicos resulta bastante coincidente con lo que otros colegas han planteado recientemente para los oasis de San Pedro. Estamos muy de acuerdo con Torres-Rouff y Hubbe respecto de que la excesiva atención prestada a la definición de fases culturales,

...serve to mask intra-ayllu diversity in issues such as interregional interaction and social standing that are only visible 
with a closer perspective... A standardized vision has oversimplified the complex human processes... processes that can be made visible through careful archaeological examinations (Torres-Rouff y Hubbe 2013:342).

Recapitulando, se ha sostenido que San Pedro de Atacama fue un punto importante dentro de la expansión altiplánica, sobre todo por sus condiciones históricas y estratégicas, las cuales habrían sido propicias para convertir a este lugar en el terminal caravanero y puesto de intercambio más meridional de Tiwanaku (Berenguer 2000). De este modo, tal interpretación supuso un proyecto comunitario conducido y protagonizado por una exitosa élite dirigente (Llagostera 1996, 2015; Núñez 1992). Esto, sin embargo, nos provoca una serie de cuestionamientos acerca de qué realmente evocan los cementerios sanpedrinos sobre la complejidad y aparente enriquecimiento de la sociedad local del período Medio. Y, en particular, nos hace sospechar del imaginario social que ofrece, puesto que constituye una respuesta muy obvia de la época y los grupos en cuestión. La arqueología, especialmente chilena, ha realizado una lectura inocente con una carga valórica homogeneizadora y hegemónica a la vez, cayendo en una especie de trampa del pasado; pues, a nuestro juicio, la materialidad en cuestión ocultaría otras intencionalidades y un orden social aún más complejo.

Intentando avanzar en otra lectura a partir de los datos disponibles, hay que pensar que no hay nada material de San Pedro en Tiwanaku, aunque sí manifestaciones de Tiwanaku en los oasis atacameños. En razón de lo anterior, proponemos que el interés por participar de un vínculo con el centro mayor no estuvo en el Titicaca, sino que radicó en la sociedad local y que el acceso a bienes exóticos respondería a sus propias dinámicas, concepciones de vida y ambiciones. Sin descartar la conexión Tiwanaku, a nuestro parecer esta no tuvo un carácter expansivo y quizás nunca estuvo dentro de un proyecto político para avanzar tan al sur. Elocuente de lo anterior es, por una parte, la falta del despliegue de un sistema de asentamiento que concrete el control Tiwanaku fuera del núcleo de origen (Stanish 2002). Y, por otra, el carácter tan marcadamente emblemático de su cultura material que, como la alfarería y también la textilería, aluden a un desarrollo local que no fue drásticamente afectado por influencias foráneas
(Agüero 2004; Agüero y Uribe 2014; Oakland 1992; Stovel 2001).

Por lo mismo, entonces, es necesario cuestionarse qué está pasando con esta sociedad que a la par de una fuerte identidad cerámica, también admite la integración, acceso y acumulación, al menos en la muerte, de una serie de elementos externos e internos que circundan sus territorios y remiten a lugares de origen. A primera vista, la cerámica homogeniza o unifica el paisaje social hasta que nos damos cuenta que hay tumbas sin vasijas y aquellas que las contienen exhiben una variabilidad sutilmente mayor que no puede reducirse a simples fases o temporalidades. A esto se suma el hecho que la diversidad se vuelve elocuente en los individuos enterrados dentro y entre los cementerios, ya sea por las características que portan desde su niñez como la deformación craneana, la dieta consumida a lo largo de su vida y los desplazamientos o cambios de residencia asociados, hasta abarcar el tratamiento funerario mismo recibido en la muerte. Por ejemplo, la deformación craneana no puede reducirse solo a los casos tabulares y circulares, tratándolos exclusivamente como indicadores de origen local o foráneo, respectivamente; así como la dieta tampoco puede tratarse de la misma manera, ya que hay una mayor diversidad que la distinción entre quienes consumen proteínas y carbohidratos o los que tienen mejor o peor salud oral según caries, desgaste o pérdida dental (Hubbe et al. 2012). En tanto que los isótopos para evaluar procedencia reconocen principalmente individuos locales, al mismo tiempo que a un acotado número de sujetos foráneos de un radio mucho más variado que el altiplano.

Reiteramos, entonces, que estas contradicciones entre diversidad e igualdad intentan ocultar o pretenden que la realidad social se entienda de una manera determinada. En efecto, el panorama arqueológico que ofrecen los cementerios sanpedrinos no permite afirmar que existen élites grandiosas ni exacerbada desigualdad, pero tampoco es capaz de contradecir que ello no estuviera ocurriendo. Cabe entonces preguntarse por qué la heterogeneidad se presenta a nivel de dieta, pero no tanto en términos de las ofrendas depositadas. Sin duda, muchos factores deben ser considerados, incluyendo las fechas de los entierros, ya que variables temporales y culturales podrían haber incidido en las diferencias dietarias entre e intra sitios, así como una mayor intensificación de contactos externos que no solo involucró a la cuenca del Titicaca (Hubbe et al. 
2011; Knudson y Torres-Rouff 2014; Nado et al. 2012; Torres-Rouff y Hubbe 2013).

A nuestro juicio, todo lo anterior no reflejaría exclusivamente una relación entre Tiwanaku y San Pedro de Atacama, sino que más bien sugiere que al interior de este último existió una gran diversidad individual y social que, además, en un momento de su desarrollo incluyó elementos tan lejanos como los del altiplano. En efecto, Torres-Rouff y Hubbe (2013) y Knudson y Torres-Rouff (2014) proponen una importante diversidad entre e intra ayllus tanto en términos dietarios como de lugar de origen y temporales. A lo anterior, nosotros agregamos la existencia de una contradicción entre homogeneidad y heterogeneidad que experimentó la sociedad sanpedrina, lo que permite inferir la gestación de una gran tensión interna, competencia y menos armonía (Núñez y Dillehay 1995). La homogeneidad material, al menos de la cerámica funeraria, seguramente fue impuesta por el colectivo y las creencias chamánicas, representadas por la recurrencia del complejo alucinógeno en un ritual mortuorio compartido (Llagostera 2006). Esta práctica encubriría distinciones individuales impulsadas por la actividad económica y el emprendimiento personal que requería habitar un lugar tan apartado en pleno desierto de Atacama.

Las comunidades locales se encontraban en esta permanente y creciente tensión a partir del periodo Formativo (Adán y Urbina 2007), pero sería en el período Medio cuando se manifiesta con mayor fuerza lo que se entendió, bajo una concepción hegemónica, como el "enriquecimiento" atacameño (Llagostera 1996). Para esos momentos es posible suponer la existencia de un grupo que intenta imponer control de esta condición individual, promoviendo una imagen unitaria y homogénea de la sociedad en el manejo de la cultura material; al igual que por medio del férreo sistema de creencias que exaltó lo sobrenatural y la muerte. Por lo tanto, en ese mundo lo individual no tendría mayor sentido e incluso pudo estar vetado; no obstante, esto no habría impedido la existencia de emprendimientos personales y familiares específicos que, de alguna manera, comenzaron a expresar diferencias con el orden impuesto. Esta condición pareciera responder a éxitos individuales, de familias y determinadas comunidades que a través del intercambio, según las cerámicas foráneas presentes, lograron nexos externos, acceso a recursos así como también ganaron prestigio y acumulación. Dicha situación pareciera expresarse en la prosperidad de los contextos funerarios de los oasis, cuya masividad es notable en Solcor 3 (Llagostera et al. 1988); mientras que en la vida cotidiana y en los asentamientos esta expresión pudo provocar divisiones y conflictos entre o al interior de los grupos.

Conforme a ello, no sería extraño que la contradicción entre el orden tradicional y las diferencias individuales redundara en mayor desigualdad y violencia interna. En este sentido, los acercamientos al rigor de la vida cotidiana analizados en traumas craneanos y post craneanos de adultos de San Pedro sugieren que existió un alto índice de violencia interpersonal a lo largo de toda la secuencia histórica documentada, ya sea previo, durante o posterior a Tiwanaku (Cocilovo et al. 2014; Costa et al. 1998). Algunos de estos investigadores establecen un índice o tasa de traumas, de 15,03\%, sobre todo en el cráneo; lo cual es evaluado como significativamente alto al ser comparado con otras poblaciones y muy semejante a sociedades insulares afectadas por gran restricción de recursos. En suma, hombres y mujeres se alimentaron y acumularon bienes en forma diferenciada, pudieron tener diversos orígenes y se encontraban por igual insertos en dinámicas de violencia. Esto fortalece la posibilidad que los grupos atacameños estuvieran envueltos en rencillas territoriales y en la defensa de recursos escasos o extremadamente focalizados (Costa et al. 1998). La conformación diversa de contextos funerarios con cierta concentración o diversidad cerámica, parafernalia alucinógena o de objetos foráneos, podrían estar remitiendo a esos poderes en conflicto, generalmente un poder dominado por los hombres si se toma en cuenta la estrecha relación entre estos y los alucinógenos en sitios como Solcor 3, donde la asociación entre ambos alcanza $72 \%$ y podría llegar al $88 \%$ de los hombres (Horta 2014; Llagostera et al. 1988). Se trataría del paralelismo social antes mencionado, en tanto dos expresiones del mismo poder masculino, de la contradicción entre chamanes y caravaneros, los que se enfrentaron durante siglos para gestar los que conocemos arqueológicamente como cultura San Pedro.

Sin embargo, lo que nos interesa finalmente destacar de este modelo de sociedad y su expresión material es que ocultarían una realidad todavía más heterogénea y desigual que anuló y subordinó la participación de otros actores. Los que incluso son 
poco o nada considerados por la disciplina como las personas sin ajuares ni ofrendas exóticas, las mujeres e incluso ciertos enfermos (p.ej., Costa y Llagostera 2014), todos aquellos que desaparecen por los cálculos, promedios e índices de significación estadística. Abogamos, por lo tanto, por el pronto reconocimiento de todos esos actores, pues su participación en la historia de San Pedro no solo permitirá mejorar nuestra comprensión de la sociedad local, sino que inclusive podrían ayudarnos a explicar el cambio ocurrido hacia el año 1.000 d.C. que dio paso al período Intermedio Tardío, sin tener que acudir a explicaciones teleológicas como un cambio climático, el colapso de Tiwanaku y el llamado "empobrecimiento" cultural de San Pedro (Bittmann et al. 1978; Costa 1988; Tarragó 1989). Como afirmamos en un trabajo anterior, las razones del cambio cultural y del Intermedio Tardío en la región, en San Pedro y el Loa, deben “... privilegiar una comprensión de la historia cultural y la evolución social desde la perspectiva de las sociedades locales y lo 'atacameño', de sus dinámicas y conflictos internos..." (Uribe y Adán 2005:264).

Agradecimientos: FONDECYT Regular 1110461, dirigido por el Dr. Sergio Flores. Los registros cerámicos originales fueron obtenidos gracias a los proyectos 1970073 y 1010735 , dirigidos por J. Berenguer y A. Llagostera. Asimismo, agradecemos al IIAM R.P. Gustavo Le Paige s.j. de San Pedro de Atacama que permanentemente nos han facilitado sus valiosas colecciones. También a los evaluadores que con sus valiosos comentarios han hecho de este manuscrito un mejor artículo.

\section{Referencias Citadas}

Adán, L. y S. Urbina 2007. Arquitectura formativa en San Pedro de Atacama. Estudios Atacameños 34:7-30.

Agüero, C. 2004. Componente Tiwanaku vs. componente local en los oasis de San Pedro de Atacama. En Textiles Andinos: Pasado, Presente y Futuro, editado por V. Solanilla, pp. 180-198. Universidad Autónoma de Barcelona, Barcelona.

Agüero, C. y M. Uribe 2014. Rethinking the Tiwanaku phenomenon in San Pedro de Atacama through the study of the textiles of Solcor 3 and their associated contexts (400-1000 AD). En Textile Society of America Symposium 2014 Proceedings. Los Angeles, CA., Estados Unidos http://digitalcommons.unl.edu

Albarracín-Jordán, J. 1996. Tiwanaku. Arqueología Regional y Dinámica Segmentaria. CID/Plural Producciones, La Paz.

Agarwal, S. 2012. A bioarchaeology of social identity. The SAA Archaeological Record 12:29-31.

Ambrose, S. 1990. Preparation and characterization of bone and tooth collagen for isotopic analysis. Journal of Archeological Science 17:431-451.

Ambrose, S. 1991. Effects of diet, climate and physiology on nitrogen isotope abundances in terrestrial foodwebs. Journal of Archeological Science 18:293-317.

Aravena, R. 1995. Isotope Hydrology and geochemistry of northern Chile groundwaters. Bulletin de l'Institute français d'études Andines 24:495-503.

Benavente, M.A., C. Massone y C. Thomas 1986. Larrache, evidencias atípicas ¿Tiahuanaco en San Pedro de Atacama? Actas del X Congreso Nacional de Arqueología Chilena. Chungara 16-17:67-74.

Bennett, W. 1956 [1934]. Excavaciones en Tiahuanaco. Biblioteca Paceña / Alcaldía Municipal, La Paz.

Berenguer, J. 1998. La iconografía del poder en Tiwanaku y su rol en la integración de zonas de frontera: una hipótesis. Boletín del Museo Chileno de Arte Precolombino 7:19-38.
Berenguer, J. 2000. Tiwanaku. Señores del lago sagrado. Museo Chileno de Arte Precolombino, Santiago.

Berenguer, J., V. Castro y O. Silva 1980. Reflexiones acerca de la presencia de Tiwanaku en el norte de Chile. Estudios Arqueológicos 5:81-93.

Berenguer, J. y P. Dauelsberg 1989. El norte grande en la órbita de Tiwanaku. En Culturas de Chile. Prehistoria, editado por J. Hidalgo, V. Schiappacasse, H. Niemeyer, C. Aldunate e I. Solimano, pp. 129-180. Editorial Andrés Bello, Santiago.

Berenguer, J., J.A. Deza, A. Román y A. Llagostera 1986. La secuencia de Myriam Tarragó para San Pedro de Atacama: un test por termoluminiscencia. Revista Chilena de Antropología 5:17-54

Bittmann, B., G. Le Paige y L. Núñez 1978. Cultura Atacameña. Serie Patrimonio Cultural Chileno, Ministerio de Educación, Santiago.

Bourdieu, P. 1977. Outline of Theory of Practice. Cambridge University Press, Cambridge.

Bravo, L. y A. Llagostera 1986. Solcor-3: Un aporte al conocimiento de la cultura San Pedro. Período 500-900 d.C. Actas del X Congreso Nacional de Arqueología Chilena Chungara 16-17:323-332.

Browman, D. 1984. Tiwanaku: development of interzonal trade and economic expansion in the Altiplano. En Social and Economic Organization in the Prehispanic Andes, editado por D. Browman, pp. 117-142. BAR International Series 1994, Oxford.

Buikstra, J. y D. Ubelaker 1994. Standards for Data Collection from Human Skeletal Remains: Proceedings of a Seminar at the Field Museum of Natural History. Arkansas Archeological Survey, Fayetteville.

Cocilovo, J., H. Varela y M. Fuchs 2014. Calidad de vida y dimorfismo sexual en la población prehispánica de San Pedro de Atacama (norte de Chile). Estudios Atacameños 47:19-32. 
Conklin, W. 1991. Tiahuanaco and Huari: architectural comparisons and interpretations. En Huari Administrative Structure, Prehistoric Monumental Architecture and State Government, editado por W. Isbell y G. McEwan, pp. 281-291. Dumbarton Oaks, Washington D.C.

Cook, A. 1994. Wari y Tiwanaku: Entre el Estilo y la Imagen. Fondo Editorial, Pontificia Universidad Católica del Perú, Lima.

Costa, M.A. 1988. Reconstitución física y cultural de la población tardía del cementerio de Quitor-6 (San Pedro de Atacama). Estudios Atacamenos 9:99-126.

Costa, M.A. y A. Llagostera 1994. Coyo 3: momentos finales del Período Medio en San Pedro de Atacama. Estudios Atacameños 11:73-107.

Costa, M.A. y A. Llagostera 2014. Leishmaniasis en Coyo Oriente. Migrantes trasandinos en San Pedro de Atacama. Estudios Atacameños 47:5-18.

Costa, M.A., A. Llagostera, F. Rothammer y C. Silva 1995. Microdiferenciación craneométrica entre poblaciones agroalfareras de San Pedro de Atacama, Chile. Actas del XIII Congreso Nacional de Arqueología Chilena. Hombre y Desierto: Una Perspectiva Cultural 9 Tomo II: 27-31.

Costa, M.A., W. Neves, A.M. de Barros y R. Bartolomucci 1998. Trauma y estrés en poblaciones prehistóricas de San Pedro de Atacama, norte de Chile. Chungara 30:65-74.

Costa, M.A., W. Neves y M. Hubbe 2004. Influencia de Tiwanaku en la calidad de vida biológica de la población prehistórica de San Pedro de Atacama. Estudios Atacameños 27:103-116.

Echenique, E. 2011. Ceramic Production in San Pedro de Atacama, Chile: A Petrographic Study of Pottery from Coyo Aldea. Master Thesis. University of Arizona, Tucson.

Fernández, J., 1978. Los chichas, los lipes y un posible enclave de la Cultura de San Pedro de Atacama en la puna limítrofe argentino-boliviana. Estudios Atacameños 6:21-35.

Finucane, B. 2006. Mummies, maize, and manure: Multi-tissue stable isotope analysis of late prehistoric human remains from de Ayacucho valley, Peru. Journal of Archaeological Science 34:2115-2124.

Foucault, M. 1992. La Microfísica del Poder. Ediciones La Piqueta, Madrid.

Giddens, A. 1995. La Constitución de la Sociedad: Bases para la Teoría de la Estructuración. Amorrortu, Buenos Aires.

Goldstein, P. 1995-96. Tiwanaku settlement patterns of the Azapa Valley, Chile. New data and the lecagy of Percy Dauelsberg. Diálogo Andino 14/15:57-73.

Goldstein, P. y B. Owen 2001. Tiwanaku en Moquegua: las colonias altiplánicas. Boletín de Arqueología PUCP 5:139-168.

Gosselain, O.P. 1998. Social and technical identity in a clay crystal ball. En The Archaeology of Social Boundaries, editado por M.T. Stark, pp. 78-106. Smithsonian Institution, Washington y Londres.

Gosselain, O.P. 2008. Thoughts and adjustments in the potters backyard. En Breaking the Mould: Challenging the Past Through Pottery, editado por I. Berg, pp. 67-79. BAR International Series 1861, Oxford.
Horta. H. 2014. Lo propio y lo ajeno. Definición del estilo San Pedro en la parafernalia alucinógena de los oasis del salar de Atacama. Chungara Revista de Antropología Chilena 46:559-583.

Hubbe, M., M. Ovideo y C. Torres-Rouff 2011. El estado de conservación de la colección osteológica Gustavo Le Paige y su contextualización cronológica. Estudios Atacameños 41:29-44.

Hubbe, M., C. Torres-Rouff, W. Neves, L. King, P. Da-Gloria y M.A. Costa 2012. Dental health in northern Chile's Atacama oases: evaluating the Middle Horizon (AD 500-1000) impact on local diet. American Jorunal of Physical Anthropology 148:62-72

Isbell, W. 1983. Shared ideology and parallel political development: Huari and Tiwanaku. En Investigations of the Andean Past: Papers of the First Annual Northeast Conference of Andean Archaeology and Ethnohistory, editado por D. Sandweiss, pp. 186-208. Cornell Latin American Studies Program, Ithaca, Nueva York.

Isbell, W. y A. Cook 1987. Ideological origins of an Andean conquest State. Archaeology 40:27-33.

Janusek, J. 2004. Identity and Power in the Ancient Andes: Tiwanaku Cities through Time. Routledge, Nueva York.

Janusek, J. 2008 Ancient Tiwanaku. Cambridge University Press, Cambridge.

Knudson, K. 2007. La influencia Tiwanaku en San Pedro de Atacama: una investigación utilizando el análisis de isótopos del estroncio. Estudios Atacameños 33:7-24.

Knudson, K. y C. Torres-Rouff 2014. Cultural diversity and paleomobility in the Andean Middle Horizon: radiogenic strontium isotope analyses in the San Pedro de Atacama oases of northern Chile. Latin American Antiquity 25:170-188.

Kolata, A. 1993. The Tiwanaku. Portrait of an Andean Civilization. Blackwell Publishers, Oxford.

Korpisaari, A. 2006. Death in the Bolivian High Plateau: Burials and Tiwanaku Society. Archaeopress, Oxford.

Lechtman, H. y A. Macfarlane 2005. La metalurgia del bronce en los Andes Sur Centrales: Tiwanaku y San Pedro de Atacama. Estudios Atacameños 30:7-27.

Le Paige, G. 1961. Cultura de Tiahuanaco en San Pedro de Atacama. Anales de la Universidad del Norte 1:19-23.

Le Paige, G. 1964. El Precerámico en la cordillera atacameña y los cementerios del Período Agroalfarero de San Pedro de Atacama. Anales de la Universidad del Norte 3, Antofagasta.

Le Paige, G. 1965. San Pedro de Atacama y su zona (14 Temas). Anales de la Universidad del Norte 4, Antofagasta.

Llagostera, A. 1995. El componente Aguada en San Pedro de Atacama. Boletín del Museo Chileno de Arte Precolombino 6:9-34.

Llagostera, A. 1996. San Pedro de Atacama: nodo de complementariedad reticular. En Integración Surandina: Cinco Siglos Después, editado por X. Albó, M. Arratia, J. Hidalgo, L. Núñez, A. Llagostera, M.I. Remy y B. Revesz, pp. 17-39. Centro de Estudios Regionales Andinos Bartolomé de las Casas, Cuzco.

Llagostera, A. 2006. Contextualización e iconografía de las tabletas psicotrópicas Tiwanaku de San Pedro de Atacama. Chungara Revista de Antropología Chilena 38:83-111. 
Llagostera, A. 2015. Albores del psicotropismo en San Pedro de Atacama. Pipas vs. tabletas. Chungara Revista de Antropología Chilena 47:489-515.

Llagostera, A., C. Torres y M.A. Costa 1988. El complejo psicotrópico en Solcor-3 (San Pedro de Atacama). Estudios Atacameños 9:61-98.

López, P., I. Cartajena y L. Núñez 2013. Análisis de isótopos estables en colágeno de huesos de camélidos de Quebrada de Tulán, Puna de Atacama, Período Formativo Temprano (ca. 3100-2400 AP). Chungara Revista de Antropología Chilena 45:237-247.

McGuire, R. 1983. Breaking down cultural complexity: inequality and heterogeneity. Advances in Archaeological Method and Theory 6:91-142.

Masuda, S., I. Shimada y C. Morris 1985. Andean Ecology and Civilization. University of Tokyo Press, Tokyo.

Menzel, D. 1964. Style and time in the Middle horizon. Ñawpa Pacha 2:1-105.

Mujica, E. 1985. Altiplano-coast relationships in the South-Central Andes: from indirect to direct complementarity. En Andean Ecology and Civilization, editado por S. Masuda, I. Shimada y C. Morris, pp. 103-140. University of Tokyo Press, Tokyo.

Munizaga, C. 1963. Tipos cerámicos del sitio Coyo en la región de San Pedro de Atacama. Actas del Congreso Internacional de Arqueología de San Pedro de Atacama, pp. 99-131. Universidad del Norte, Antofagasta.

Murra, J. 1972. El "control vertical" de un máximo de pisos ecológicos en la economía de las sociedades andinas. En Visita a la Provincia de León de Huánuco en 1562, Iñigo Ortiz de Zúñiga, editado por J. Murra, pp. 429-472. Universidad Emilio Valdizán, Huánuco.

Nado, K., S. Marsteller, L. King, B. Daverman, C. Torres-Rouff y K. Knudson 2012. Examining local social identities through patterns of biological and cultural variation in the Solcor ayllu, San Pedro de Atacama, Chile. Chungara Revista de Antropología Chilena 44:341-357.

Neves, W. y M.A. Costa 1997. Adult stature and standard of living in the prehistoric Atacama desert. Current Anthropology 39:278-281.

Niemeyer, H., D. Salazar, H. Horta y F.T. Peña-Gómez 2015. New insights into the Tiwanaku style of snuff trays from San Pedro de Atacama, Northern Chile. Latin American Antiquity 26:120-136.

Núñez, L. 1984. Tráfico de Complementariedad de Recursos Entre las Tierras Altas y el Pacífico en el Área Centro-Sur Andina. Tesis doctoral, University of Tokyo, Tokyo.

Núñez, L. 1992. Cultura y Conflicto en los Oasis de San Pedro de Atacama. Editorial Universitaria, Santiago.

Núñez, L. y T. Dillehay 1995 [1978]. Movilidad Giratoria, Armonía Social y Desarrollo en los Andes Meridionales: Patrones de Tráfico e Interacción Económica. Universidad del Norte, Antofagasta.

Oakland, A. 1992. Textiles and ethnicity: Tiwanaku in San Pedro de Atacama, north Chile. Latin American Antiquity 3:316-340.

Orellana, M. 1984. Influencias altiplánicas en San Pedro de Atacama. Estudios Atacameños 7:197-208.
Orellana, M. 1985. Relaciones culturales entre Tiwanaku y San Pedro de Atacama. Diálogo Andino 4:247-257.

Ortiz, C., R. Aravena, E. Briones, F. Suárez, C. Tore y J.F. Muñoz 2013. Sources of surface water for the Soncor ecosystem, Salar de Atacama basin, northern Chile. Hydrological Sciences Journal 59:336-350.

Owen, B. 2005. Distant colonies and explosive collapse: the two stages of the Tiwanaku diaspora in the Osmore drainage. Latin American Antiquity 16:45-80.

Ponce, C. 1972. Tiwanaku: Espacio, Tiempo y Cultura. Academia Nacional de Ciencias de Bolivia, La Paz.

Posnansky, A. 1957. Tihuanacu: La Cuna del Hombre Americano (vols. III y IV). Ministerio de Educación, La Paz.

Roberts, A., D. Pate, B. Petruzzelli, C. Carter, M. Westaway, C. Santoro, J. Swift, T. Maddern, G. Jacobsen, F. Bertuch y F. Rothhammer 2013. Retention of hunter-gatherer economies among maritime foragers from Caleta Vitor, Northern Chile, during the late Holocene: evidence from stable carbon and nitrogen isotopic analysis of skeletal remains. Journal of Archeological Science 40:2360-2372.

Salazar, D., V. Figueroa, D. Morata, B. Mille, G. Manríquez y A. Cifuentes 2011. Metalurgia en San Pedro de Atacama durante el Período Medio: nuevos datos, nuevas preguntas. Revista Chilena de Antropología 23:123-148.

Santana, F., M.J. Herrera y M. Uribe 2012. Acercamiento a la paleodieta en la costa y quebradas tarapaqueñas durante el Período Formativo: análisis de isótopos estables a partir de tres casos de estudio. Boletín de la Sociedad Chilena de Arqueología 41-42:109-126.

Santana-Sagredo, F., J. Lee-Thorp, R. Schulting y M. Uribe 2014. Isotopic evidence for divergent diets and mobility patterns in the Atacama Desert, Northern Chile, during the Late Intermediate Period (AD 900-1450). American Journal of Physical Anthropology. DOI: 10.1002/ajpa.22663.

Sponheimer M., T. Robinson, A. Roeder, J. Hammer, B. Passey, A. West, T. Cerling, D. Dearing y J. Ehleringer 2003. Nitrogen isotopes in mammalian herbivores: Hair $\delta^{15} \mathrm{~N}$ values from a controlled feeding study. International Journal of Osteoarcheology 13:80-87.

Stanish, C. 2002. Ancient Titicaca: The Evolution of Complex Society in Southern Peru and Northern Bolivia. University of California Press, Los Angeles.

Stone, P. 2012. A bioarchaeology of sex and gender. What is the difference and why is it important? The SAA Archaeological Record 12:38-40.

Stovel, E. 1997. Habitational Analysis and Cultural Contact at Coyo Aldea, Northern Chile: The Surface Deposits. Master Thesis. State University of New York, Binghamton.

Stovel, E. 2001. Patrones funerarios de San Pedro de Atacama y el problema de la presencia de los contextos Tiwanaku. Boletín de Arqueología PUCP 5:375-395.

Stovel, E. 2005. The Archaeology of identity construction: ceramic evidence from Northern Chile. En Global Archaeological Theory: Contextual Voices and Contemporary Thoughts, editado por P. Funari, A. Zarankin y E, Stovel, pp. 145-166. Springer/ Kluwer, Nueva York. 
Szpak, P., J. Millaire, C. White y F. Longstaffe 2012. Influence of seabird guano and camelid dung fertilization on the nitrogen isotopic composition of field-grown maize (Zea mays). Journal of Archaeological Science 39:3721-3740.

Tarragó, M. 1976. Alfarería típica de San Pedro de Atacama. Estudios Atacameños 4:37-67.

Tarragó, M. 1989. Contribución al Conocimiento Arqueológico de las Poblaciones de los Oasis de San Pedro de Atacama en Relación con los Otros Pueblos Puneños, en Especial, al Sector Septentrional del Valle Calchaquí. Tesis de Doctor en Historia, Especialidad Antropología, Facultad de Humanidades y Artes, Universidad Nacional de Rosario, Rosario.

Thomas, C., M.A. Benavente y C. Massone 1985. Algunos efectos de Tiwanaku en la cultura de San Pedro de Atacama. Diálogo Andino 4:259-274.

Thomas, C., C. Massone y M.A. Benavente 1984. Sistematización de la alfarería del área de San Pedro de Atacama. Revista Chilena de Antropología 4:49-119.

Tieszen, L., E. Iversen y S. Matzner 1992. Dietary reconstruction based or carbon, nitrogen and sulfur stable isotopes in the Atacama Desert, Northern Chile. Proceedings of the First World Congress on Mummy Studies, pp. 427-441. Museo Arqueológico y Etnográfico de Tenerife, Santa Cruz de Tenerife.

Torres, C. y W. Conklin 1995. Exploring the San Pedro de Atacama/ Tiwanaku relationship. En Andean Art: Visual Expression and its Relation to Andean Beliefs and Values, editado por P. Dransart, pp. 78-108. Worlwide Archaeology Series Vol. 13, Avebury.

Torres-Rouff, C. 2002. Cranial vault modification and ethnicity in Middle Horizon San Pedro de Atacama, Chile. Current Anthropology 43:163-171.

Torres-Rouff, C. y M. Hubbe 2013. The sequence of human occupation in the Atacama oases, Chile: a radiocarbon chronology based on human skeletal remains. Latin American Antiquity 24:330-344.

Uribe, M. 2004. Alfarería y Metodología. Aportes y Proyecciones de los Estudios Cerámicos en la Arqueología del Norte Grande de Chile. Tesis de Magíster, Universidad de Chile, Santiago.
Uribe, M. 2006. Arqueología de Pica-Tarapacá (Norte de Chile). Reflexiones acerca de la complejidad y la desigualdad social en los Andes Centro Sur (1000-1450 DC). Estudios Atacameños 31:91-114.

Uribe, M. 2011. Un recorrido a través de la tipología cerámica y el valor social de los objetos en arqueología. En Teoría Arqueológica en Chile. Reflexionando en Torno a Nuestro Quehacer Disciplinario, editado por P. Ayala y F. Vilches, pp. 169-187. QILLCA, Universidad Católica del Norte, Santiago.

Uribe, M. y L. Adán 2005. Arqueología, etnohistoria y etnografía. Apuestas metodológicas en la investigación cultural del Norte Grande. Actas del XVI Congreso Nacional de Arqueología Chilena, pp. 263-274, Tomé.

Uribe, M. y C. Agüiero 2001. Alfarería, textiles y la integración del Norte Grande de Chile a Tiwanaku. Boletín de Arqueología PUCP 5:397-426.

Uribe, M. y C. Agüero 2004. Iconografía, alfarería y textilería Tiwanaku: elementos para una revisión del período Medio en el Norte Grande de Chile. Actas del XV Congreso Nacional de Arqueología Chilena. Chungara Revista de Antropología Chilena 36 Número Especial Tomo 2:1055-1068.

Varela, H. y J. Cocilovo 2011. Divergencia fenotípica en los oasis de San Pedro de Atacama, norte de Chile. Estudios Atacameños 42:101-112.

Varela, V., M. Uribe y L. Adán 1993. La cerámica arqueológica del sitio "Pukara" de Turi 02-TU-002. Actas del XII Congreso Nacional de Arqueología Chilena. Boletín del Museo Regional de La Araucanía Tomo II:107-112.

Wallace, D. 1980. Tiwanaku as a symbolic empire. Estudios Arqueológicos 5, Antofagasta.

Walrath, D.E., P. Turner y J. Bruzek 2004. Reliability test of the visual assessment of cranial traits for sex determination. American Journal of Physical Anthropology 125:132-137.

Zizek, S. 2003. El Sublime Objeto de la Ideología. Siglo Veintiuno Editores, Buenos Aires. 